\title{
Cuestión nacional y nacionalismos en el Pensamiento social cristiano
}

\author{
Josep M. Margenat Peralta S. I.'
}

Resumen: Este estudio muestra de manera precisa que el Pensamiento social cristiano no legitima ni ampara las pretensiones nacionalistas. Desde una prolongada atención a la realidad antropológica y cultural de la nación por la Iglesia, que ha sido afirmada con intensidad y claridad desde la plena edad media, el magisterio social pontificio a lo largo del siglo XX se ha pronunciado reiteradas veces de forma crítica y atenta sobre el fenómeno del nacionalismo.

Para situar la reflexión que estrictamente pertenece al magisterio pontificio contemporáneo, en los dos primeros apartados se aclaran los posibles sentidos, a veces ambiguos, de palabras como nación, Estado, nacionalismo y patriotismo, entre otras. El estudio, a partir de un análisis de la documentación existente, pretende mostrar la complejidad de la cuestión y la necesidad de una hermenéutica explícita para tratar de la nación y del nacionalismo.

Después de la introducción, se trata de la realidad de la nación como idea y como comunidad, de la cuestión nacional vista por el Pensamiento social cristiano, y del "giro culturalnacional" de éste a partir de 1980. Por último en la conclusión se afirma que dentro de la continuidad existe una auténtica evolución en el magisterio pontificio contemporáneo que, sin embargo, no afirma la validez del nacionalismo político independentista. La nación, y su correlato el nacionalismo no identificable sin más con la primera, necesitan una cuidadosa y critica labor hermenéutica, si no se quiere derivar hacia posiciones excluyentes, arbitrarias o exageradas, en ningún caso fundamentadas.

La posición crítica del Pensamiento social cristiano siempre ha considerado el llamado nacionalismo exacerbado como una proposición no aceptable y ha valorado sin embargo el patriotismo, el verdadero amor a la patria. Ciertamente, el pontificado de Juan Pablo ll supuso cambios semánticos sobre la nación y nuevas perspectivas, profundizando en la dimensión antropológico-cultural de la misma. De ninguna manera, sin embargo, los sucesivamente

' Departamento de Humanidades y Filosofía. Universidad Loyola Andalucía. 
matizados pronunciamientos de Juan Pablo Il sirven para legitimar posiciones nacionalistas políticas. En los últimos años no ha habido cambios significativos en el magisterio.

Palabras clave: Giro cultural-nacional, hermenéutica política, iusnaturalismo, nación política, nación cultural, nacionalismo exacerbado, patriotismo universalista.

Fecha de recepción: 15 de junio de 2018.

Fecha de admisión definitiva: 19 de diciembre de 2018.

\section{National question and nationalisms in Christian social thought}

Abstract: This study shows in a precise manner that the Christian social thought does not legitimate nor shelter the nationalistic claims. From a protracted attention to the anthropological and cultural reality, of the nation, which with intensity and clearness has been stated since the full middle age, the Papal social teaching, throughout the XXth century has, time and time again, pronounced itself in a critic and attentive way about the phenomenon of nationalism.

To situate the reflection which strictly belongs to the contemporary papal teaching, in the two first parts, the possible meanings, which at times are ambiguous, are clarified: words such as nation, State, nationalism, patriotism, among others. Starting from an analysis of the extant documentation, the study intends to show the complexity of the question, and the need for an explicit hermeneutics in order to discuss about the nation and about nationalism.

After the introduction, the reality of nation as an idea and as a community is dealt about, likewise the national issue seen by the Christian social thought, and the "cultural-national turn" of this thought, since

\section{La question nationale et les nationalismes} dans la Pensée sociale chrétienne

Résumé: Cette étude montre de manière précise que la Pensée sociale chrétienne ne donne pas de légitimité ni ne justifie les prétentions nationalistes. À partir d'une attention prolongée sur la réalité anthropologique et culturelle de la nation, qui a été affirmée avec intensité et clarté depuis le Moyen-Age, le magistère social pontifical s'est prononcé de nombreuses fois, tout au long du XXème siècle, $d$ 'une manière critique et attentive sur le phénomène du nationalisme.

Pour centrer la réflexion qui appartient strictement au magistère pontifical contemporain, le sens des termes, parfois ambigus, tels que nation, État, nationalisme ou patriotisme, entre autres, est clarifié dans les deux premiers paragraphes. L'étude, à partir d'une analyse de la documentation existante, prétend montrer la complexité de la question et la nécessité d'une herméneutique explicite pour traiter les sujets de nation et nationalisme.

Après l'introduction, nous abordons le sujet de la réalité de la nation comme idée et comme communauté, de la question nationale vue par la Pensée sociale chrétienne ainsi que du tournant culturel-national de celle-ci à partir de 1980. Finalement, dans 
1980. Lastly, at the conclusion it is affirmed that within the continuity there is an authentic evolution in the contemporary Papal teaching which, however, does not affirm the validity of the independence promoting political nationalism. The nation, and its correlative, the nationalism, which without more a do is not identifiable with the first, needs of a very careful and critical hermeneutical work, if one does not want to derive toward exclusive, arbitrary, or exaggerated positions which in no case are truly well founded.

The critical position of the Christian social thought has always considered the so called exaggerated nationalism as a non acceptable proposition, and yet it has valued patriotism, the true love of the country or fatherland. Certainly, the pontificate of John Paul II did suppose semantic changes about the nation and new perspectives deepening on its anthropological-cultural dimension. In no way, however, the successively nuanced declarations of John Paul II are of help to legitimate political nationalistic positions. In the past recent years there have been no significant changes on the Teaching of the Church.

Key words: Cultural-national turn, political hermeneutics, iusnaturalism, political nation, cultural nation, exacerbated nationalism, universalist patriotism. la conclusion, nous affirmons que, dans la continuité, il existe une authentique évolution du magistère pontifical contemporain qui, cependant, n'affirme pas la validité du nationalisme politique indépendantiste. La nation et son corrélat le nationalisme, non identifiable à première vue avec la première, a besoin d'un travail herméneutique méticuleux et critique si l'on ne veut pas dériver vers des postures discriminatoires, arbitraires ou exagérées, et en aucun cas fondées.

La position critique de la Pensée sociale chrétienne a toujours considéré le nationalisme «exagéré» comme une proposition nonacceptable et a, cependant, toujours mis en valeur le patriotisme, l'amour réel de la patrie. Certainement, le pontificat de Jean Paul II a impliqué des changements sémantiques sur la nation ainsi que de nouvelles perspectives, en approfondissant dans la dimension anthropologique-culturelle de celle-ci. Cependant, en aucun cas, les déclarations de Jean Paul II, successivement nuancées, permettent de légitimer des positions politiques nationalistes. Lors des dernières années il n'y a pas eu de changements significatifs dans le magistère.

Mots clé: Tournant culturel-national, herméneutique politique, jusnaturalisme, nation politique, nation culturelle, nationalisme exacerbé, patriotisme universaliste.

\section{Introducción}

Existen textos que casi hemos olvidado. Al volver a ellos, nos encontramos tesis que, sin cierta perspectiva, carecerían hoy de la inteligibilidad tan necesaria. "Comprender" (Verstehen) un fenómeno histórico, social o cultural, no tiene que significar siempre su legitimación o validación, pero sin la adecuada comprensión, y la labor hermenéutica que se inserta en ella, es imposible acercarse a una valoración ética convincente. Importa mucho intentar primero "entender" (Erklären) 
para luego comprender. Si no se consigue esta intelección, hay que preguntar a los interlocutores por las razones que aducen, mirando cómo entenderlas. En ese esfuerzo hermenéutico situamos esta reflexión sobre la cuestión nacional y los nacionalismos, pues pretendemos orientar nuestro comportamiento práxico y, por otro lado, ser fieles a la inspiración y a la orientación que nos proporciona el cuerpo del Pensamiento social cristiano (PSC, a partir de ahora) y su metodología.

Creemos ya superada la contraposición propia de otros tiempos entre una concepción metafísico-deductiva y otra concepción socio-histórica inductiva en el PSC. A partir de Caritas in Veritate, es posible una tercera posición hermenéutico-antropológica que no niega ninguna de las dos anteriores, sino que las integra, superando la disyunción. ${ }^{2}$ Hoy no podemos soslayar un pronunciamiento que, aunque siempre plural en sus posibilidades dentro de la concepción cristiana del orden social, quede abierto a un esfuerzo de recíproca comprensión de las posiciones y motivos diferentes a los propios que, aun reconociendo las diferencias, permita a unos y otros confiar en las posibilidades de caminar juntos y de lograr la unidad, tras un examen leal de comportamientos e ideas, para animar y renovar la sociedad secular desde el patrimonio ético que surge y se orienta desde el humanismo cristiano integral.

Como pedía Pablo VI en 1971, los católicos, y también sus organizaciones, tienen que expresar las exigencias concretas de la fe cristiana para una transformación justa y, por consiguiente, necesaria de la sociedad, de manera que así la "calidad de mundo" que trae causa de la Encarnación de Dios en silencio (tanto amó Dios al mundo) sea "escuchada", y eventualmente recibida, por la sociedad secular. Sólo así la Palabra encarnada puede ser operante en la acción de los cristianos al servicio de sus hermanos, en los puntos donde se juegan estos su existencia y su porvenir ${ }^{3}$.

La cuestión nacional es uno de esos puntos donde los ciudadanos de España y los de Cataluña se juegan ("nos jugamos") nuestra existencia y nuestro porvenir, es decir, la forma de comunidad política que queremos configurar y pactar para vivir juntos ${ }^{4}$.

2 J. M. MARGEnAt (2018) "Fundamentación antropológica y hermenéutica de Populorum progressio", en José Sols LUCIA, coordinador (2018) La humanidad en camino: A los cincuenta años de la encíclica Populorum progressio, cuya edición está prevista por editorial Herder (Barcelona) en 2019.

${ }^{3}$ PABLO VI (1971) Carta apostólica Octogesima adveniens (14-5-1971), nn. 50-51, cf. AAS 63 (1971) 403ss.

${ }^{4}$ Cf. CONSEJO dE REDACCIÓN (2016) "España y Cataluña: la reconstrucción de un pacto": Revista de Fo- 
No nos cabe duda de que podemos afirmar que esta forma de "vivir juntos", ni está de antemano decidida, ni tiene razones evidentes para ordenarse de una $\mathrm{u}$ otra forma; tampoco el PSC tiene principios suficientes para una ordenación indiscutible, pues como fue declarado por el Concilio Vaticano II "una misma fe cristiana puede conducir a compromisos diferentes", pero sí puede dar criterios u orientaciones para ordenar los fines pretendidos al bien común y al respeto de valores esenciales en un horizonte de humanización, de mayor justicia para la solución de los problemas y de ordenación al servicio de las personas y de las comunidades.

Para orientar la praxis política es necesario tener presentes los criterios enunciados por el papa Benito XVI en Deus caritas est (2005):

A. La distinción entre Estado e Iglesia es propia del cristianismo, es decir el reconocimiento de la autonomía de las realidades temporales; el orden justo de la sociedad y del Estado como tal realidad autónoma, es una tarea principal de la política; la justicia es el objeto y la medida intrínseca de toda política, pues su origen y meta, de naturaleza ética, están en la justicia; para alcanzarla, la razón ha de purificarse constantemente a partir de la fe cristiana que abre horizontes más allá de la propia razón, para que ésta desempeñe mejor su cometido.

B. La Iglesia aporta su propia ayuda para que lo justo, aquí y ahora, pueda ser reconocido y puesto en práctica, aunque no sea tarea de la Iglesia hacer valer políticamente esta doctrina, sino servir a la formación de las conciencias en la política para que crezca la percepción de las exigencias de la justicia y la disponibilidad para construir un orden social y estatal justo, una tarea fundamental que debe afrontar cada generación.

C. La Iglesia no puede ni debe emprender la empresa política de realizar la sociedad más justa posible, es decir, no debe sustituir al Estado, pero tampoco

mento Social 71, 5-53. He tratado sobre la "cuestión catalana", tema que no abordo en este estudio, en otros escritos anteriores como "Pueblo en construcción": El Ciervo. Revista de pensamiento y cultura 65 (2016) n 759, p. 33, y "Catalanismo cívico ahora": El Ciervo. Revista de pensamiento y cultura 66 (2017) n ${ }^{\circ} 765$, p. 35; "Eine Grafschaft Spaniens? Der Katalonienkonflikt und die katalanische Kirche": Stimmen der Zeit 236 (2018), fasc. 8, 534-546 y "Obertura catalana y catalanismo democrático": Razón y Fe 278 (2018) 31-48. En ellos expreso con bastante claridad una posición, por lo que me permito presentar en este estudio de manera clara, pero general, la posición del PSC ante la cuestión nacional y sobre los nacionalismos, eximiéndome de precisar más sobre la cuestión catalana que obviamente informa el contexto en el que el estudio se ha realizado en los últimos tres años. Por otro lado, en los próximos meses debería aparecer una investigación más amplia sobre el factor católico y cuestión nacional en el catolicismo europeo contemporáneo, que completará esta aproximación. 
quedarse al margen en la lucha por la justicia, sino insertarse en la misma a través de la argumentación racional y debe despertar de las fuerzas espirituales, sin las cuales la justicia no puede afirmarse ni prosperar, pues se cerraría a la inteligencia y a las exigencias del bien común ${ }^{5}$.

En este escrito queremos partir también de la realidad concreta y que nos es próxima, la relación entre Cataluña y España en la que se juegan sentimientos, proyectos y realidades, que denominamos nación, nacionalismo o independentismo, y soluciones, como federación, recentralización o independencia, sobre las que el PSC puede hacer algunas aportaciones de acuerdo con los criterios, antes enumerados que propuso el papa Ratzinger.

También la Iglesia catalana, el pueblo de Dios que peregrina en tierras catalanas, tiene su percepción de esta realidad concreta y próxima. Sirvan las siguientes manifestaciones de épocas diferentes en una misma revista representativa de la reflexión de la Iglesia catalana sobre su realidad, Qüestions de vida cristiana (1981 y 2013) como expresión de esta conciencia:

... hoy la Iglesia catalana (...) reconoce su realidad peculiar, que no es equiparable con la de las otras Iglesias de los pueblos de España. Hemos de proclamar alto en un momento en que al intento de "armonización política" corresponde el intento de "armonización eclesial", de la que es portavoz (capdavanter) el cardenal Tarancón (sic). En ambos casos se trata de una reducción de la realidad catalana a estereotipos (...) que demuestran de una manera palpable la imposibilidad de comprender la periferia desde el centro ${ }^{6}$.

Las afirmaciones de 1981 subrayaban unos hechos de los que se partía sin cuestionar ni fundamentar: peculiaridad irreductible de la realidad catalana e imposibilidad de que esta peculiaridad fuese comprendida. A partir de ambas afirmaciones, el mismo editorial apuntaba consecuencias y avanzaba propuestas:

No se trata, ni política ni eclesialmente, de "armonizar", sino de afirmar el derecho a ser diferentes, lo que no significa poner en cuestión ni la solidaridad, ni las relaciones

${ }^{5}$ Cf Benedicto XVI (2005) Encíclica Deus caritas est, nn 26-29; J. M. MARGenat (2006) "Justicia y amor: dos dimensiones, una realidad. Sobre la encíclica Deus caritas est": Revista de Fomento Social 61, 319-359. Una posición similar puede encontrarse en CONGREGACIÓN PARA LA DOCTRINA DE LA FE (2002) L'impegno dei cristiani (Nota doctrinal sobre algunas cuestiones relativas al compromiso y la conducta de los católicos en la vida política), de 24-XI-2002: I'Osservatore romano 17-I-2003, 6-7, también consultable en Congregación para la doctrina de LA fe (2008) Documentos 1966-2007, Madrid, Católica, (BAC-673), 708-722.

6 Nota editorial de presentación del número 109 (noviembre-diciembre de 1981) sobre "La Iglesia y la nacionalidad catalana" ("L'Església i la nacionalitat catalana"), de la revista entonces publicada por la Abadia de Montserrat, Qüestions de vida cristiana, p. 3. 
de justicia y buen entendimiento (entesa) con las otras lglesias ${ }^{7}$ y las otras naciones que configuran el Estado español${ }^{8}$.

En 2013, treinta y dos años más tarde, la misma revista publicaba un nuevo número monográfico dedicado a "La independència" citando al abad de Montserrat Josep M. Soler y una frase del "famoso" (según el editorial) discurso a la UNESCO de Juan Pablo II (París, 2-6-1980), se recogía la pregunta " $\dot{2}$ No existen en el mapa de Europa y del mundo, naciones que tienen una maravillosa soberanía histórica procedente de su cultura y que sin embargo al mismo tiempo están privadas de su plena soberanía?", a la que el padre abad respondía:

Hoy [2013] deseamos y proclamamos aún más [que en 1963] que la autoconciencia de los catalanes y la articulación de nuestra nación en el Estado actual han puesto de manifiesto (desvetllat) la convicción de que entre los derechos humanos también está el de decidir nuestro futuro. Si los cristianos catalanes se veían reflejados en la Pacem in terris, ${ }^{10}$ la evolución misma de la doctrina social de la Iglesia ha hecho nuevas aportaciones sobre el tema de las nacionalidades ${ }^{11}$.

\footnotetext{
7 (sic)

${ }^{8}$ lb., p. 4.

9 Editorial del número 247 (2013) sobre "La independència". Actualmente la revista Qüestions de vida cristiana es publicada por la Abadia de Montserrat y la Fundació Joan Maragall.

${ }^{10}$ En el editorial se hace referencia a 1963 y a la encíclica Pacem in terris de aquel año (3-VI-1963), que al menos en cinco puntos puede referirse a las cuestiones de la independencia y relacionadas: los ciudadanos de un Estado autónomo o independiente (n. 37), la estructura de los poderes públicos no es definitiva (n. 61), la vitalidad y desarrollo de las minorías (n. 89), las posibles controversias y negociaciones (n. 119) y el reconocimiento de derechos para todos los pueblos y naciones. Cfr. J. AMAT (2018) Largo proceso, amargo sueño. Cultura y política en la Cataluña contemporánea (edición en catalán, 2015), Barcelona, Tusquets, 268: "El impacto de la Pacem en el antifranquismo catalanista también fue sustancial". Unas páginas más adelante el autor resalta la coincidencia de las palabras del abad A. M. Escarré con lo que había escrito Josep Benet: "Cataluña es uno de los ejemplos típicos a los que puede aplicarse la encíclica en lo referente a minorías étnicas" (275).
}

11 J. M. SOLER (2013) "Els valors del catalanisme, com a factor de cohesió social": Qüestions de vida cristiana, n 247 (sobre "La independència") 155-163. 


\section{La nación, una idea y una comunidad}

\section{I. La idea de nación: la ineludible necesidad de interpretar}

La nación no es una realidad natural, sino una idea sobre esa realidad ${ }^{12}$. Ninguno de los factores que explican otras formaciones sociales basta para dar cuenta de la nación como una realidad diferenciada. Ésta es una realidad "inventada", es decir creada interpretativamente a partir de una construcción. Aunque exista un carácter nacional, es decir, elementos comunes al comportamiento de las personas que se dicen parte de una realidad nacional, también existen otros comportamientos antropológicamente esenciales comunes a personas que no pertenecen a la misma comunidad nacional. La nación no es un fenómeno directamente observable, puesto que sólo se hace explícita a partir de los sentimientos que se atribuyen a la misma o de las actitudes que suscita. Esta representación que la personas se hacen de su ser colectivo, no es tampoco algo irreal o simplemente inexistente, sino un "mito" con capacidad para aglutinar y movilizar los sentimientos, las conciencias y las actitudes humanas. ${ }^{13} \mathrm{La}$ nación es un "mito inventado" de voluntad de pertenencia y de voluntad de existencia.

Juan Pablo II se refirió a la nación como esa "gran sociedad" [tipografía diferenciada en el original], a la que pertenece el hombre en base a particulares vínculos culturales e históricos con una doble característica esencial: es la gran "educadora» pues en ella cada persona asume los contenidos y valores de la cultura (de una nación) y es la gran encarnación histórica y social del trabajo de todas las generaciones. Todo esto hace que el hombre concilie su más profunda identidad humana con la pertenencia a la nación ${ }^{14}$. Podemos entender la nación como la relación de unas personas con otras con vínculos culturales e históricos que les aporta una mayor identidad humana ${ }^{15}$.

${ }^{12}$ Cf G. BuRDEAU (1990) "Nation": Encyclopaedia universalis 5-9 (5). Cf CONSEJO DE REDACCIÓN (2010) "«La ilusión de la identidad». El actual debate europeo": Revista de Fomento Social 65; Juan Pablo II en su discurso ante la ONU (octubre de 1995) lo expresó así: teniendo en cuenta la dificultad de definir el concepto mismo de "nación", que no se identifica a priori y necesariamente con el de Estado.

${ }^{13} \mathrm{CF}$ LI. DUCH (2011) "Consideraciones antropológicas sobre identidad y tradición, a partir del documento episcopal Raíces cristianas de Cataluña (1985)": Revista de Fomento Social 66, 73-85 (otra versión en Ll. DUCH (2012) Religión y comunicación, Barcelona, Fragmenta, 328-341) y J. CARRERA (2015) "¿independencia o interdependencia?": Razón y Fe 273, 39-48.

14 JuAn Pablo II (1981) Carta encíclica Laborem exercens (14-IX-1981) n. 10, AAS (1981).

${ }^{15} \mathrm{Cf}$. Encyclopaedia universalis, cit. supra. 
El origen de la reflexión ética del PSC, original y profunda, sobre la nación podemos empezar a verlo en la escolástica ibérica tardía, también conocida como segunda escolástica, que reformuló la concepción aristotélico-tomista de comunidad política (la politéia) al tener que afrontar lo nuevo en lo otro, es decir la existencia de comunidades políticas diferentes a las hasta entonces conocidas. Nos hallamos ante el comienzo del actual derecho internacional. Si por un lado, hasta ese momento las comunidades existentes habían sido consideradas societates perfectae, era cada vez más evidente que hacia fuera no tenían la misma autosuficiencia. Nacía así el sistema "comunidad internacional" sobre el que el PSC habría de reflexionar al menos en dos direcciones: la regulación de las relaciones internacionales interestatales y la solidaridad de las naciones, en sí mismas insuficientes, pues eran parte de una familia humana siempre mayor. Al menos desde el siglo XVI, ésta ha sido la doble clave que ordenará el PSC: superación de los egoísmos nacionales y búsqueda de consecuencias realistas para el desarrollo de la interdependencia.

\subsection{De la comunidad de nacimiento a la comunidad de pertenencia}

Los romanos distinguían entre populus (ellos mismos, los ciudadanos de Roma) y nationes (que eran todos los otros), distinción que también era similar en los griegos (politaí y barbarikoi). Así, la Biblia Vulgata distinguía entre populus to que la Iglesia más adelante denominará populus messianicus' ${ }^{16}$ y pagani, los extraños al pueblo) ${ }^{17}$. En la edad media las nationes sirven para agrupar en las universidades o en los concilios a los originarios de una misma tierra. Todos son el mismo pueblo, aunque pertenezcan a naciones diferentes. Había una lengua común, el latín, y lenguas propias diferentes. Había tres comunidades esenciales: la ekuméne o universitas cristiana (el orbis), las ciudades (civitates) y los lugares de nacimiento (las nationes). Éste es el tiempo originario de un nacionalismo "natural", basado en los hechos directos y primarios de la vinculación a una comunidad (Gemeinschaffl) y reconocido por el derecho natural. Éste es un nacionalismo particularista, pero no excluyente, pues es compatible con el universalismo cristiano, superador del particularismo de Israel: de pueblo elegido a pueblo peregrino convocante de todos. Hay dos patrias: la patria universal y común (celestial o ecuménica: civitas christiana, res publica christiana) y la patria propia: la patria minor, la terra pa-

\footnotetext{
${ }^{16}$ Cf. CONCILIO VATICANO II (1964) Constitución dogmática sobre la lglesia Lumen gentium (21-XI-1964), nn 9 y 13.

17 Una presentación clara en J. A. GonZÁlez CASANOVA (1981) "Pàtria, nació, poble": Qüestions de vida cristiana, n 109 (sobre "L’Església i la nacionalitat catalana") 8-15.
} 
trum (fatherland), el país (el pagus, le pays, il paese, la terra); la patria propia en la que se nace y se vive es la nación. Tomás de Aquino, y aún más la escolástica tardía, realizó una síntesis que preparaba el advenimiento de la fase siguiente, aunque todavía en el horizonte de una universitas christiana.

Con Tomás la nación, hasta entonces considerada una comunidad étnica o particular de una tierra, adquiere el carácter de populus a que antes me he referido y pasa a ser una comunidad política en el sentido legal romano. La nación se configura vocacionalmente como civitas o Estado. Toda nación es populus, es decir, toda realidad nacional natural tiende a ser una nación constituida con un régimen político regido por leyes basadas en el derecho natural: el pueblo natural o nacional es una comunidad política, libre y radicalmente democrática.

El gran cambio se dio con el comienzo de las monarquías territoriales (ya llamadas nacionales) en el siglo XV, que culminó en la configuración nacional-estatal fijada en Westfalia (1648): fueron más de dos siglos de progresivo desarrollo del nuevo concepto de nación. Las monarquías nacionales aceleraron y consolidaron, sobre todo en la Europa occidental (Inglaterra, Portugal, España, Francia), la politización de los naturales (los nacidos en los territorios respectivos) y con ello la politización de la nación o patria. A partir de ese siglo XV, quizá desde finales del anterior, en Europa hubo dos procesos paralelos: en el oeste triunfó el proceso de centralización política y territorialización administrativa, mientras en el centro y en el este europeos siguió existiendo un estado de latencia nacional en Estados compuestos plurinacionales $v$ otras formas organizativas existentes (hasta los procesos de risorgimento de la nacionalidad latente, unos triunfantes en la segunda mitad del siglo XIX (principio de las nacionalidades) o principios del s. XX (doctrina de W. Wilson en el discurso de 8-I-1918 y hechos posteriores, al final de la primera guerra mundial, incluida la independencia de Irlanda en 1922), y otros bloqueados hasta mucho más tarde (1991 y posteriores: repúblicas bálticas, repúblicas yugoslavas, etc.).

Una persona es de una nación por nacimiento (natural) o por pertenencia (decidida o convenida). Este proceso se ha configurado en la Europa moderna en tres momentos que expongo a continuación. Según el historiador italo-aostano Federico Chabod, ser parte o miembro de una nación no era en la edad media todavía el factor estructurante de una pertenencia, sino tan sólo la afirmación de una lengua, unas costumbres, unos usos cívicos o unas instituciones comunes (primer momento), a partir del nuevo orden europeo derivado de las guerras de religión y de Westfalia, pero ya desde los siglos XVIII y XIX se afirmó el deseo de pertenencia como voluntad de existencia, como decisión de ser juntos (segundo momento). 
En el siglo XVIII surgió un nuevo nacionalismo, totalmente diferente al nacionalismo "natural y cultural" anterior, que se fue afianzando a lo largo del siglo XIX. Este nacionalismo era "artificial", pues se "construyó" por una decisión, vinculada a un "espíritu", actúa en el supuesto estado de latencia nacional impulsando un resurgimiento, una renaixença, una verdadera resurrección (fiesta cristiana en la que, por ejemplo, se celebra el día de la patria vasca), un risorgimento de algo que estaba camuflado, olvidado, oculto; la referencia fundamental no es ya la tierra de origen, ni tampoco muchas veces la lengua o la raza, aunque ambos factores sigan teniendo un papel importante en la configuración del nacionalismo artificial, sino el nacionalismo de la decisión, el nacionalismo político. Este nacionalismo aunque tiene un pretendido origen natural, se concibe a sí mismo y en relación a otros como una forma indirecta y secundaria de vinculación, como sociedad (Gesellschaff). Con los hermanos von Schlegel, Fichte y sobre todo con Herder (Volkgeist), todos ellos alemanes ${ }^{18}$, como es sobradamente conocido, pero también con la famosa conferencia de E. Renan, Qu'est ce qu'une nation? (1882) ${ }^{19}$, se va dando forma acabada a la concepción de nación como realidad electiva. La concepción idealista alemana, no racionalista, y romántica, la que tuvo un influjo duradero en todos los nacionalismos europeos del Ochocientos, pretende que el pueblo realiza un proyecto divino encarnado en el mundo y tiene un destino sobrenatural y supratemporal. Es el tiempo de Wagner y de su invención de la mitología germánica de los mitos fundadores de la nación alemana. Este nacionalismo, tan diferente del nacionalismo francés, expresa un espiritualismo místico y mítico frente al laicismo secularizado y racionalista de un Estado del pueblo soberano de individuos libres. Son las dos formas de nacionalismo decimonónico.

Alguien, una persona o un grupo familiar, étnico, etc., es parte de una nación porque ejerce (o puede ejercer cuando quiera) el derecho a pertenecer, vinculado y arraigado en un sentimiento diferencial, el derecho a decidir serlo. Alguien es

${ }^{18}$ Cfr. L. Gonzalo Dízz (2018), El viaje de la impaciencia. En torno a los orígenes intelectuales de la utopía nacionalista, Barcelona, Galaxia Gutenberg.

${ }^{19}$ Es cierto que Renan en su famosa conferencia de 11-III-1882 en Sorbona subrayaba elementos más propios de la concepción francesa basada en la vinculación a una ley republicana y laica (de pueblo, laós), mientras que la concepción alemana partía de una identificación étnica. En un sentido respondían al mismo segundo momento del nacionalismo, aunque el modelo francés divergiese del alemán. Decía Renan:

Una nación es un alma, un principio espiritual. Dos cosas que, a decir verdad, no son sino una, constituyen esta alma, este principio espiritual. Una está en el pasado, la otra en el presente. Una es la posesión en común de un rico legado de recuerdos; la otra el consentimiento actual, el deseo de vivir juntos, la voluntad de seguir haciendo valer la herencia indivisible recibida. 
"nacional" de alguna comunidad no por haber nacido en ella, en un lugar, al menos no sólo por eso, sino porque "decide" serlo. Una nación es nación porque "decide" ser nación. Esta forma peculiar de "decisionismo" 20 forma parte del proceso de construcción (nation building) de los Estados-nación, inclusivos y excluyentes a su vez, del que derivan los dos modelos actualmente vigentes: las naciones étnicogenealógicas y las naciones cívico-territoriales ${ }^{21}$. A su vez, E. Passerin d'Entreves, jurista italo-aostano, ha subrayado que a partir de este momento se pasa de una concepción de la nación desde el sentimiento de pertenencia al del control de la pertenencia (tercer momento). Cuando, como en Francia, el nacionalismo en lugar de ser "espiritual" (Volkgeist) sea racional se alcanzará una concepción jurídicopolítica de la nación (la que expresa Sièyes, en la que el pueblo, diferenciado de las élites nobiliarias, de los extranjeros ocupantes) es el sujeto histórico que libera de un orden irracional. Es el nacionalismo de un pueblo.

Las naciones étnico-genealógicas encuentran su razón de ser en la protección de la subjetividad nacional, la de las personas y la colectiva, puesto que éste se basa en la relación de unas personas con otras por medio de los vínculos culturales e históricos que aportan su identidad humana (valores, usos cívicos, costumbres, instituciones comunes, lengua, derecho propio, etc.). Esta concepción de la nación étnico-genealógica incluye a todos los que deciden ser parte de esa nación a partir de su sentimiento de pertenencia, y excluye obviamente que esas personas puedan compartir otra genealogía de pertenencia y que esa realidad nacional pueda identificarse, subsumirse o diluirse en otra Nación (en este caso nación política, de donde la mayúscula).

Estas naciones-sin-Estado están en proceso de constitución como sujeto político para ejercer y controlar el deseo de pertenencia y, en su momento, independizarse

\footnotetext{
20 Pío XII (1943) Con sempre, criticaba la pretendida superioridad del nacionalismo sobre el ordenamiento jurídico, al convertir a aquél en la raíz última del instinto jurídico y considerar las decisiones como último imperativo e inapelable norma de los gobernantes.
}

${ }^{21}$ Cf A. D. SмiтH (1997) La Identidad Nacional (National Identity, 1991), Madrid, Trama. Desde su escrito fundamental Theories of Nationalism (1971, 21983), el profesor Anthony Smith (Oxford y LSE, Londres) ha publicado importantes estudios por los que es considerado el politólogo de referencia en cuestiones sobre nacionalismo: The Ethnic Origins of Nations (1986), Nations and Nationalism in a Global Era (1995), Nationalism and Modernism (1998), Myths and Memories of the Nation (1999), The Nation in History. Historiographical Debates about Ethnicity and Nationalism (2000), Chosen Peoples: Sacred Sources of National Identity (2003), The Antiquity of Nations (2004), Cultural Foundations of Nations: Hierarchy, Covenant and Republic (2008) y Ethno-symbolism and Nationalism: A Cultural Approach (2009). Del título de 2000 hay una edición italiana revisada La nazione. Storia di un'idea (A. Campi, ed.), Soveria Mannelli, Rubbetttino, 54+123. La nota preliminar de 2018 (pp. vii-xxxvii) y la introducción de 2007 (pp. xxxix-liv), ambas de Campi. 
de otra Nación que hasta ahora la ha sometido, controlado o intentado exterminar. También podríamos llamarlas en origen nación cultural con tendencia a ser Nación política. Antes del siglo XVII, en un primer tiempo estas naciones étnico-genealógicas se han comprendido a sí mismas como naciones culturales, aunque más tarde, sobre todo desde finales del siglo XIX y en el primer tercio del siglo XX, al afirmarse el llamado "principio de las nacionalidades" se fue afirmando también el carácter de "sujeto político" de esas naciones culturales, de naciones sin Estado que deben llegar a ser Naciones identificadas con un poder político soberanos y la correspondiente administración.

Las naciones cívico-territoriales se configuran a sí mismas como Naciones-Estado ${ }^{22}$, inclusivas de todos los que son ciudadanos de un territorio. La nación cívico-territorial excluye inicialmente cualquier otra formulación o pretensión de nación: ésa es su forma de control de pertenencia. Ser ciudadano equivale a ser miembro de la nación. El genérico "nación" que antes valiera para incluir en sí a las realidades nacionales culturales, a las realidades nacionales cívicas y a las naciones-Estado políticas, ahora conlleva irremediablemente, pero a veces también abriendo procesos sempiternamente irredentistas, la "necesidad" de ser Nación o verse abocadas a no ser nada.

Esta concepción es aplicable tanto en Estados con varias pertenencias nacionales (sentimentales, culturales), Estados pluri-nacionales, como la mayoría de los actuales, como en Estados uni-nacionales, que son la excepción, aún más ahora en que aumenta el mestizaje de población a causa de las fuertes corrientes migratorias inter-nacionales. La nación cívico-territorial tiene una única fuente de legitimidad, de la que procede una legalidad unitaria, y equivale a la nación política.

En resumen, podemos sintetizar tres concepciones de nación y tres tiempos de desarrollo de la misma:

- naturalista, que también podríamos llamar iusnaturalista (nación étnico-genealógica o nación cultural);

- positivista-política (nación cívico-territorial o nación política);

- espiritualista-idealista (nación como proyecto de pertenencia por decisión nacionalista no nacional).

\footnotetext{
22 Uso deliberadamente la mayúscula para nación cuando pretendo diferenciarla como nación política y nación en minúscula en casi todos los otros casos, como en "nación" cultural.
} 
Los tiempos son: afirmación de unos vínculos comunes; deseo de pertenencia y afirmación de una realidad electiva que es resultado de una decisión y que otorga identidad; control de pertenencia. El siguiente cuadro puede leerse de forma diacrónica lo que explicaría una evolución en la que a cada momento correspondería una concepción, o de forma compleja por medio de la que se explicarían situaciones diferentes que pueden coexistir dentro de una misma concepción.

\section{CUADRO I. Concepciones y tiempos de la nación}

\begin{tabular}{|c|c|c|c|}
\hline Concepciones & \multirow[t]{2}{*}{ Iusnaturalista } & $\begin{array}{l}\text { Positivista- } \\
\text { política }\end{array}$ & $\begin{array}{c}\text { Idealista- } \\
\text { nacionalista }\end{array}$ \\
\hline Tiempos & & \multicolumn{2}{|c|}{ Pueblo } \\
\hline Vínculos comunes & $\begin{array}{l}\text { Nación étnico- } \\
\text { genealógica } \\
\text { Nación cultural } \\
\text { - País }\end{array}$ & & \\
\hline $\begin{array}{l}\text { Decisión de } \\
\text { pertenencia }\end{array}$ & & $\begin{array}{l}\text { Nación } \\
\text { cívico-territorial } \\
\text { Nación política }\end{array}$ & $\begin{array}{l}\text { Nación inclusiva } \\
\text { / excluyente } \\
\text { Nación "decisio- } \\
\text { nista-identitaria" }\end{array}$ \\
\hline $\begin{array}{l}\text { Control de } \\
\text { pertenencia }\end{array}$ & & $\begin{array}{l}\text { Pueblo de ciuda- } \\
\text { danos (bajo ley) }\end{array}$ & $\begin{array}{l}\text { Pueblo como } \\
\text { sujeto político }\end{array}$ \\
\hline
\end{tabular}

Elaboración propia.

\subsection{La comunidad nacional: la insoslayable realidad social de la nación}

Las ideas políticas de Jacques Maritain pueden aportar el marco conceptual para una interpretación de la realidad social de la nación" ${ }^{23}$. Para el "filósofo en la ciudad", como ha sido conocido, vivir juntos no significa simplemente ocupar el mismo lugar en un territorio, vivir juntos significa participar como personas, en virtud de una libre aceptación, "en unos sufrimientos comunes y en una tarea co-

${ }^{23}$ Cf J. MARITAIN (1953) L'Homme et l'État (Chicago 1949), París, Cerf. Cita de J. y R. MARITAIN (1990) Oeuvres complètes 9 [1947-1951], 471-736; cf J.-D. DURAND (2013) "Jacques Maritain et la nation": Cahiers Jacques Maritain $n^{\circ} 67$ (diciembre) 44-55. Entre nosotros ha tratado a fondo y con rigor este tema J. GIRÓ I PARís (1995) El pensament polític de Carles Cardó i de Jacques Maritain, Barcelona, Institut d'Estudis Catalans. 
mún, [pues en el actual momento] el mejor sinónimo de vivir juntos es sufrir juntos". Esta aceptación de sufrir juntos no nace del amor de unos ciudadanos por otros, sino por el amor común por la tarea común y el bien común. "¿Qué sufrimientos estamos dispuestos a aceptar?", se pregunta Maritain, a lo que responde: "los debidos a la solidaridad".

Maritain escribió sobre este tema sobre todo en l'Homme et l'État, publicado primero en inglés, cuando, siendo profesor de Princeton (1949), residía en los Estados Unidos. La obra fue traducida más tarde al francés (París 1953), edición ésta que se suele considerar definitiva. Es su gran escrito de filosofía política. Desde 1945, hubo intensas reflexiones sobre la nación durante la inmediata postguerra y tras la noche de los totalitarismos, los fascismos y la guerra civil europea. Conviene retener este contexto.

En él la propuesta maritainiana tiene relación directa con el iusnaturalismo, siendo muy distante del jacobinismo francés, pero que sobre todo se comprende en el contexto de un nuevo federalismo europeo postnacional que es una síntesis constitucional de paz y de justicia.

La identificación y confusión sistemáticas entre estado, nación y soberano es "una plaga de la historia moderna". Para Maritain, aunque no haga referencia explícita a la distinción establecida ya en 1887 por Ferdinand Tönnies entre comunidad y sociedad (Gemeinschaft, Gesellschaff), la nación es una comunidad, no una sociedad, la nación es quizá la más completa y una de las más complejas comunidades de la civilización. Maritain aporta una definición sobre nación:

Una nación es una comunidad de personas que toman conciencia de ellas mismas tal como la historia les ha hecho, se adhieren al tesoro de su pasado y se estiman tal como se reconocen o imaginan $\operatorname{ser}^{24}$.

Esta concepción de nación manifiesta una vocación histórica que identifica el "alma de un pueblo" con un territorio. La geografía y la historia se unen en esta manera de entender la nación, una vocación histórica común que privilegia el ius soli frente al ius sanguinis.

Maritain distingue entre ejemplos de nación-Estado y afirma que algunos de estos en el fondo no son naciones en sentido auténtico, sino conglomerados, o Estados

${ }^{24}$ Cf. J. MARITAIN, L'Homme et l'État, en J. y R. MARITAIN (1990) Oeuvres complètes, Friburgo Suiza París, Universitaires - Saint Paul, 9 [1947-1951], 486 (cf. J. MARITAIN (1983) El Hombre y el Estado, Madrid, Encuentro - Fundación Humanismo y Democracia, 19). 
sin nación. Francia responde al modelo de nación-Estado que tiene como base la libertad de los ciudadanos en la constitución del cuerpo político que ha ido autoengendrándose a lo largo del tiempo, tras un conjunto de pruebas y en respuesta a ellas desde esta historia de libertad. No obstante, también en Francia y en otras naciones-Estado, el concepto de nación y el de Estado llegaron a confundirse y se mezclaron de manera explosiva y desastrosa ${ }^{25}$ tras lo que Maritain pudo afirmar que el Estado-nación no es sino la forma exasperada de nación ${ }^{26}$. La identificación entre el cuerpo social (la comunidad), el territorio y el Estado llevaron a una uniformidad que hizo enormemente rígida la forma nación.

A partir de esta reflexión crítica, Maritain denuncia la confusión entre nación y Estado, el mito del Estado nacional y el así llamado principio de las nacionalidades por el que cada grupo nacional debe constituirse en Estado separado ${ }^{27}$, y llega a la conclusión sobre la deriva de una exasperada voluntad de poder del Estado, pretendiendo imponer por la fuerza de la ley un pretendido tipo de "genio nacional".

La nación se diviniza y el nacionalismo la pervierte. La nación es agredida por el nacionalismo, pues se trata de una ilusión, contraria al derecho natural ya que según éste las comunidades políticas tienden a ser configuradas por lo que son y no deben configurarse por lo que ideológicamente son constreñidas a ser. Este nacionalismo es destructor de la civilización y de la nación como cuerpo político. El nacionalismo, según Maritain, acaba desembocado en el culto ciego a la patria, el culto nacional, a veces racista, que toma la función superior de la moral o de la religión. En términos más actuales y hoy suficientemente estudiados, contrastados y debatidos, el nacionalismo se convierte en una religión de sustitución ${ }^{28}$.

El patriotismo, el amor a la patria, es una de las formas más elevadas de la caridad colectiva que es la caridad política ${ }^{29}$. En otro contexto, Pío XI ponía como

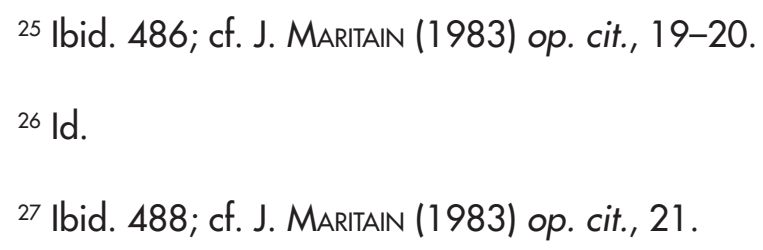

${ }^{28}$ La expresión fue propuesta por I. SÁEZ DE LA FUENTE (2002), aunque entre nosotros la realidad ha sido analizada, no con el mismo rigor en todos los casos, por Elorza, Juaristi o Llobera siguiendo la senda abierta por los estudios de Emilo Gentile sobre el fascismo italiano y otros movimientos como "religión políica"; cfr. Le religioni della politica. Fra democrazie e totalitarismi, Roma 2001, Laterza (traducción inglesa: Politics as Religion, Princeton University Press 2006).

${ }^{29}$ Expresión usada por Pío Xl en un discurso a los dirigentes de la Federación Universitaria Católica de 
ejemplo a santa Juana de Arco, patrona de Francia desde 1922, a la que la Iglesia canonizó en 1929. Hay un verdadero patriotismo católico que se opone al espíritu de violencia del nacionalismo que absolutiza el interés y, aún más, el "mito" de la nación. Hay un amor natural por la patria que desemboca en un amor por la humanidad (caritas humano generis). Maritain denunciaba el error "nacionalitario" 30 . En l'Homme et l'État lo expresaba así:

Sabemos que un sentimiento nacional profundo y potente es una base normal y sana para la misión que deben realizar los pueblos, como sabemos que el nacionalismo es un peligro grave para ese sentimiento nacional en sí mismo, así como para la paz en el mundo, puesto que el nacionalismo no es más que un sustituto irracional que oculta la ausencia de ideal constructivo y de auténtica fuerza nacional ${ }^{31}$.

Esta identificación indebida, la exasperación de la nación, lleva a Maritain a criticar el concepto de soberanía que tiene su origen en Jean Bodin y Thomas Hobbes, por tanto un concepto relativamente reciente, por el que se llegó a justificar y a divinizar el poder absoluto de los reyes. Cuando tras la revolución francesa, y los ensayos de Sièyes, esta noción ha pasado a ser atributo del pueblo, el "pueblo soberano", considerado como gobernándose a sí mismo, separadamente y por encima de sí mismo, se ha llegado a una afirmación falsa, aunque aparentemente clara.

El pueblo soberano elimina en realidad la auctoritas del pueblo, reificándola en un poder soberano que concede al Estado. Éste se convierte así en destructor del cuerpo político. La noción de soberanía, escribía Maritain, debería ser sustituida por la de autoridad, como por otra parte desarrolló enérgicamente Gaston Fessard. ${ }^{32}$ El Estado moderno y soberano se basa en una ficción: es una persona.

Italia (FuCI), aludida en la Constitución pastoral sobre la Iglesia en el mundo de hoy Gaudium et spes (7-XII-1965) del Concilio Vaticano II, n 75.

${ }^{30}$ En esto coincide con una larga tradición en el pensamiento político cristiano de la que es muestra esta frase de un tratadista de finales del siglo XVI: "ante todas cosas digo que hay razón de estado (...) pero que esta razón de estado no es una sola, sino dos: una falsa y aparente y otra sólida y verdadera, (...) una que del estado hace religión, otra que de la religión hace estado"; cf. P. DE RIBADENEYRA (1595) Tratado de la religión y virtudes que debe tener el Príncipe cristiano para gobernar y conservar sus Estados, contra lo que Nicolás Maquiavelo y los políticos de este tiempo enseñan (edición de Vicente DE LA FUENTE), Madrid, 1868, Biblioteca de autores españoles (BAE, 60), 456.

${ }^{31}$ Cf. J. MARITAIN, L'Homme et l'État, en J. y R. MARITAIN (1990) Oeuvres complètes 9 [1947-1951]

${ }^{32}$ Cf. G. FESSARD (2015) Autorité et bien commun (1944), Nanterre (Francia), Ad solem, 255. La obra, redactada en 1941-1942 debió esperar para su publicación al final de la guerra; más tarde fue revisada varias veces por Fessard. 
La noción de Estado soberano parte de la concepción de éste como una persona supra-humana, que goza de un derecho de soberanía absoluta, en la pretensión confusa de ser una persona superior al cuerpo político al que domina o absorbe en sí mismo. Pero, como de hecho, el Estado no es una persona, sino un mecanismo impersonal de leyes abstractas y poderes concretos, ese mecanismo, cuando la idea falsa llegue a desarrollar todas sus potencialidades, y el orden natural de la realidad sea alterado, va convertirse en algo inhumano por ser suprahumano: el Estado ya no estará al servicio de las personas, sino éstas al servicio de los fines particulares del Estado, un poder impersonal.

Para Maritain, tan sólo si mantenemos la distinción entre nación, Estado y cuerpo político es posible el pluralismo democrático, así como el respeto de la persona humana que debe estar en el corazón de toda construcción social de la realidad y de búsqueda del bien común. El cuerpo político, para Maritain, integra en una unidad superior a los grupos familiares, los grupos sociales intermedios, una multiplicidad de sociedades particulares que proceden de la libre iniciativa social y deben ser tan autónomos como sea posible. Toda sociedad política debe ser pluralista para que el cuerpo político sea viable y vital y ni éste, ni la vida social en su complejidad, queden absorbidos por el Estado.

El Estado es menos que el cuerpo político, pues éste responde a la complejidad de relaciones subsidiarias entre autoridades parciales y particulares, articuladas con la autoridad suprema del Estado. Maritain es, según Durand, el antitotalitario por excelencia que denuncia la noción hegeliana despótica y absolutista del Estado totalitario y divinizado ${ }^{33}$. El Estado ciertamente es superior a los otros órganos del cuerpo político según Maritain, pero eso no significa que sea superior al cuerpo político o que esté por encima de él: el Estado es inferior al cuerpo político en tanto que todo, y está al servicio del cuerpo político en tanto que todo ${ }^{34}$.

De estas convicciones, acrecentadas y asentadas en su experiencia norteamericana (de 1939 a 1944 y desde retorno en 1948 hasta 1969), surgió la propuesta maritainiana de la federación de pueblos como la mejor organización para superar la competencia entre las naciones, la lucha de intereses nacionales y finalmente las guerras que "usan a las naciones como instrumentos", exasperando los nacionalismos rivales ${ }^{35}$.

${ }^{33}$ Cf. J. MaritalN, L'Homme et l'État, en OEuvres complètes 9 [1947-1951], 495.

${ }^{34}$ Ibid.

${ }^{35}$ Cf. "L'idée de fédération n'est pas une idée simple", en J. y R. MARITAIN (1990) OEuvres complètes 8 
Ya al comienzo de su presencia en los Estados Unidos (1940) Maritain había desarrollado esta proposición en la conferencia "Europa and the Federal idea". La federación había de ser la ocasión de una refundación del Estado moderno, así como de las relaciones entre los Estados, libres del riesgo de los totalitarismos y de la estatolatría. Maritain "veía" así una Europa federal, en cuyo núcleo estará una Alemania federal, libre de la "pasión pangermanista" y del "imperialismo prusiano". La idea federal europea podría servir de inspiración para una concepción del gobierno mundial desde una organización fundada sobre la libre adhesión y cooperación de las naciones, una organización de la comunidad internacional conforme a la justicia y a la amistad.

Esta idea de Maritain coincidía con la expresión que Alcide De Gasperi en 1954 ante la Conferencia Parlamentaria Europea, quien, poco antes de su muerte, se declaraba preocupado por el bien común de las patrias europeas, de la patria europea. Para De Gasperi, como para Maritain, Europa y las naciones europeas no se excluían, sino que la Europa democrática se enriquecía en la diversidad de las naciones porque se abría a la alteridad. El proyecto "degasperiano" se basaba en la propuesta maritainiana, en la dialéctica entre nación y Europa, "de la nación hacia Europa, más allá de la nación para Europa"36.

\section{Evolución del Pensamiento social cristiano ante la cuestión nacional}

En esta parte trataré de presentar la evolución (...) de la doctrina social de la Iglesia sobre la cuestión nacional, así como de analizar cuáles han sido las nuevas aportaciones de esa doctrina sobre el tema de las nacionalidades, siguiendo esas dos indicaciones del texto citado anteriormente de Josep M. Soler. Las tomas de posición del PSC sobre la cuestión nacional (la nación y el nacionalismo) no son frecuentes ni abundantes, salvo las del comienzo del pontificado de Pío XI (1922), las de los años inmediatamente anteriores a la segunda guerra mundial (1938-1939) del mismo Papa y las más conocidas de Juan Pablo II en 1980 y 1995, en el contexto del fin de la guerra fría que reabría cuestiones que quedaron

[1944-1946], 470-471 y "L'Europe et l'idée fédérale", en J. y R. MARITAIN (1990) OEuvres complètes 7 [1939-1943], 995-1016.

${ }^{36} \mathrm{Cf} \mathrm{J.-D.} \mathrm{DuRAND} \mathrm{(2013)} \mathrm{"Jacques} \mathrm{Maritain} \mathrm{et} \mathrm{la} \mathrm{nation":} \mathrm{Cahiers} \mathrm{Jacques} \mathrm{Maritain} \mathrm{n} 67$ (diciembre) $44-55$ (55). 
sin resolver en 1918 y en 1945, es decir en las dos postguerras mundiales. No podemos, pues, afirmar que sobre esta cuestión se haya ido creando un cuerpo de pensamiento sólido y contrastado, ${ }^{37}$ si bien es cierto que a partir de la intervención de Juan Pablo II ante la UNESCO (París 1980) hubo un giro importante del PSC ante la cuestión nacional. Hasta los tiempos más recientes, el PSC siempre ha tratado de la nación como realidad cultural (o socio-cultural) más que como realidad política. Como veremos, ni siquiera la irrupción "nacional" de Juan Pablo II en 1980 supuso un cambio radical de paradigma, antes bien el papa polaco, apelando a su experiencia personal (sentimientos) y su pertenencia a una nación, subrayó la identidad cultural subyacente a la subjetividad personal y a la subjetividad nacional-cultural, en la medida en que ésta es creadora y fundamento de las identidades personal y comunitaria.

En el recorrido que sigue, trataremos en primer lugar de los pronunciamientos y reflexiones sobre el nacionalismo inmoderado, anteriores al fin de la guerra fría, después ensayaremos una comprensión de la posición del papa Wojłyla y, con él, del PSC entre 1980 y $1995 .{ }^{38}$

\section{I. El patriotismo universalista frente al nacionalismo inmoderado}

León XIII (encíclica Libertas, 1888) comenzó a referirse a la nación en términos morales y espirituales, línea de pensamiento en que siguió Pío XI, quien se pronunció en diversas ocasiones frente a lo que él llamó "nacionalismo inmoderado", "exacerbado" o "exagerado", según las traducciones, que otros han llamado hipertrofia del patriotismo ${ }^{39}$. Ya en la encíclica programática del pontificado Ubi arcano, escribió:

\footnotetext{
${ }^{37}$ Una visión bastante completa, lógicamente sólo hasta la fecha de su aparición como libro, puede encontrarse en J. L. GUTIÉRREZ GARCíA (1971) Conceptos fundamentales en la Doctrina Social de la lglesia, Madrid, Centro de Estudios Sociales del Valle de los Caídos, III, pp. 161-170 ("nación"), 170-175 ("nacionalismo"), 351-356 ("patria") y 545-550 ("pueblo"). El autor sostiene que hay precedentes inmediatos sobre el tema en León XIII y Pío XI y un tratamiento más moderno en Pío XII y Juan XXIII, que refleja las mutaciones de la nación como realidad "en esta época de progresiva continentalización y aun mundialización" (op. cit., III, 161). El diccionario abreviado de J. L. GUTIÉRREz GarCía (1973) La concepción cristiana del orden social, Madrid, Centro de Estudios Sociales del Valle de los Caídos, 404, recoge en la voz "Nación" (236-242) lo esencial sobre la cuestión con referencias que alcanzan a Octogesima adveniens (1971).

${ }^{38}$ Una visión historiográfica completa puede encontrarse en COMPTE GRAU, M.T. (2005) "El nacionalismo en la Doctrina Social de la Iglesia", ciado en bibliografía, pp. 361-442.

${ }^{39}$ Pío XI (1932) encíclica Caritate Christi compulsi.
} 
Este mismo amor [bajo el velo de bien público y de patriotismo] de la patria y de la raza, fuente potente de múltiples virtudes y de actos de heroísmo cuando está regulado por la ley cristiana, no deja de contener un germen de injusticia y de numerosas iniquidades, si transgrediendo las reglas de la justicia y del derecho, degenera en un nacionalismo inmoderado ${ }^{40}$.

Las víctimas de ese nacionalismo inmoderado olvidan que todos los pueblos, en tanto que parte de la familia humana universal, están unidos en la fraternidad, pues, como recuerda el Papa citando el libro de los Proverbios: la justicia eleva a las naciones, el pecado es la vergüenza de los pueblos (Prov 14: 34), ya que, como advierte sabiamente san Agustín, los logros de un pueblo no está definitivamente adquiridos ni excluyen amenazas de ruina:

Porque en esta tierra, el reinado de los buenos no es beneficioso tanto para ellos cuanto para las empresas humanas. Al contrario, el reinado de los malos es pernicioso sobre todo para los que ostentan el poder, puesto que arruinan su alma por una mayor posibilidad de cometer crímenes. En cambio, aquellos que les prestan sus servicios sólo quedan dañados por la propia iniquidad. En efecto, los sufrimientos que les vienen de señores injustos no constituyen un castigo de algún delito, sino una prueba de su virtud. Consiguientemente, el hombre honrado, aunque esté sometido a servidumbre, es libre. En cambio, el malvado, aunque sea rey, es esclavo, y no de un hombre, sino de tantos dueños como vicios tenga ${ }^{41}$.

El nacionalismo exagerado hacía olvidar, según afirmaba Pío XI, en ese mismo documento, la "fraternidad universal", ${ }^{42}$ algo parecido a lo que ocho años más tarde, en el contexto de los entonces recientes Pactos lateranenses y de la también reciente crisis bursátil de Nueva York con repercusiones mundiales, ambos de 1929, decía el Papa en su discurso a los cardenales en la Navidad de 1930:

(...) aún es más difícil que dure la paz entre los pueblos y entre los Estados, si en lugar del verdadero y genuino amor patrio reina y se impone un egoísta y duro nacionalismo, lo que es decir odio y envidia del mutuo deseo de bien, desconfianza y sospecha en lugar de confianza fraterna, competencia y lucha en lugar de cooperación concorde, ambición de hegemonía, de predominio en lugar de respeto y de tutela de todos los derechos, especialmente los de los débiles y los pequeños ${ }^{43}$.

40 Pío XI (1922) encíclica Ubi arcano, n. 20: AAS 14 (1922) 682.

${ }^{41}$ Agustín de Hipona, De civitate Dei, IV: 3.

${ }^{42}$ Pío XI, Ubi arcano, loc. cit.

${ }^{43}$ Discurso La condizione della vera pace a los cardenales y a la curia (24-XII-1930); cf. Bertetto, cit., II, 456-464 (461). El texto, "questo importante (según Bertetto) discorso" no aparece en www.vatican. va (consulta 10-VIII-2016). 
Reconocía Pío XI cuatro años después, en Mit brennender Sorge, como sus antecesores, la existencia de un nacionalismo justo, moderado, templado, aunque ponía la atención sobre todo en el creciente nacionalismo exacerbado. Ese mismo año, el Santo oficio condenó el libro de Alfred Rosenberg El mito del siglo XX (Der Mythus des 20. Jahrhunderts), incluyéndolo en el Índice y criticando la proclamación de una nueva fe mítica, nacional, una nueva religión, en ese caso alemana, condenación reiterada un año después ${ }^{44}$. El papa Pío XI aprobó la resolución de condena el 9 de febrero de 1934, es decir, dos semanas después de que Hitler nombrara a Rosenberg jefe ideológico del partido (NSDP) y promotor de la Weltanschauung nazi. Así decía el documento del Santo oficio:

Este libro desprecia y rechaza completamente todos los dogmas de la Iglesia católica, e incluso los mismos fundamentos de la religión cristiana. Defiende la necesidad de fundar una nueva religión y una nueva Iglesia alemana. Enuncia el principio, según el cual, hoy es necesario que haya una nueva fe mítica de la sangre, una fe en la que se cree que la naturaleza divina del hombre puede ser defendida a través de la sangre, una fe apoyada por una ciencia que establece que la sangre nórdica representa ese misterio que supera y que se sustituye a los antiguos sacramentos. ${ }^{45}$

En 1937, en la encíclica dirigida a la Iglesia católica alemana, Mit brennender Sorge (14-III-1937), se hacía una crítica de toda absolutización del pueblo -o nación-y del estatismo como idolatría:

Si la raza o el pueblo, si el Estado o una forma determinada del mismo, si los representantes del poder estatal u otros elementos fundamentales de la sociedad humana tienen en el orden natural un puesto esencial y digno de respeto, con todo, quien los arranca de esta escala de valores terrenales elevándolos a suprema norma de todo, aun de los valores religiosos, y, divinizándolos con culto idolátrico, pervierte y falsifica el orden creado e impuesto por Dios, está lejos de la verdadera fe y de una concepción de la vida conforme a ésta ${ }^{46}$.

La Pascua del año 1937, la llamada por Hilari Raguer "Pascua de las tres encíclicas", en la que finalmente no hubo una sobre la guerra de España, dio a la luz estos documentos sobre las situaciones de Alemania, sobre el comunismo ateo, especialmente en la URSS, y sobre México: Mit brennender Sorge, Divini Redemp-

${ }^{44}$ Cfr. F. Guerrero (dir.) El magisterio pontificio contemporáneo, cit., 562, nª 9.

${ }^{45}$ AAS 26 [1934] 93. Un año después, por un decreto de 19 de julio de 1935 fue condenado también el libro de Rosenberg An die Dunkelmänner unserer Zeit. Eine Antwort auf die Angriffe gegen den "Mythus des 20. Jahrhunderts" (AAS 28 [1935] 304-305).

${ }^{46}$ N. 12, AAS 29 (1937) 145-167. Puede consultarse en www.vatican.va y en F. GueRreRO (dir.) El magisterio pontificio contemporáneo, Madrid 1992, BAC, II, 556-574. 
toris y Firmissimam constantiam (Nos es muy), respectivamente. Desde la firma del Concordato de 1933 el gobierno nazi había iniciado una progresiva lucha -el 26-VII-1935, l'Osservatore romano hablaba de Kulturkampf- y persecución contra los católicos alemanes, como por otra parte contra los judíos, con medidas totalitarias. Los obispos alemanes, entre ellos Karl J. Schulte, Michael von Faulhaber y Clemens A. G. von Galen, protestaron con claridad y fuerza frente al mito de la sangre y de la raza y Pío XI condenó una moral utilitaria de carácter colectivo puramente subjetivista, que identificase el derecho con la utilidad nacional.

Un año más tarde, en la primavera de 1938, se seguían desarrollando en toda Europa movimientos de "nacionalización de las masas" (Mosse) que generaban el rechazo, si no el odio, de unas naciones contra otras; nos encontrábamos en vísperas del comienzo de la segunda guerra mundial, al poco tiempo del Pacto de Múnich entre Hitler y Chamberlain. El Papa condenó el nacionalismo exagerado o malentendido (esagerato, malinteso) anunciando la primicia de un "ineditum": la invitación a los superiores generales religiosos, a través de sus respectivos procuradores, de que se guardaran de aquella maldición que es el nacionalismo exagerado, en contraste evidente con la doctrina católica, pues su espíritu es contrario a la fe. ${ }^{47}$

Ese nacionalismo, entre otras, tuvo consecuencias pastorales pues provoca la esterilidad apostólica, al levantar barreras entre las personas. Papa Ratti dirigiéndose al Capítulo general de unas religiosas de origen francés les advierte ante un nacionalismo exagerado con estos términos: idea equivocada, erróneo, peligroso, en la que todo su espíritu es contrario a la doctrina cristiana, una verdadera forma de apostasía. ${ }^{48}$ Pocos días después vuelve a pronunciarse contra el espíritu particularmente detestable de separatismo y nacionalismo exagerado, que, por no ser religioso ni cristiano, acaba por no ser ni siquiera humano: católico quiere decir universal, no racista, nacionalista, separatista, a lo que añade: Hay algo peor que el racismo y el nacionalismo, [...que es] el espíritu que lo dicta. ${ }^{49}$

Unos días después, todavía en el verano de 1938, papa Ratti se dirigió otras dos veces a los estudiantes del colegio De propaganda Fide, donde había alumnos de

${ }^{47} \mathrm{lbid}$.

${ }^{48}$ Pío XI (1961) Discorsi (ed. D. BerTetTo), Roma, Editrice Vaticana, 769-770: "Alle suore de Nostra Signora del Cenacolo" (15-VII-1938).

${ }^{49}$ Pí XI (1938) Discorsi (ed. D. BerTetTo), Roma 1961 (21985), Editrice Vaticana, 775: "Agli assistenti ecclesiastici della Gioventú di Azione Cattolica" (21-VII-1938). 
treinta y siete naciones distintas, y más tarde a los profesores de Acción católica, subrayando en los tres momentos la "catolicidad" (universalidad) de la Iglesia. Si en el discurso a los asistentes eclesiásticos de la Juventud de AC había criticado las tendencias racistas, en el segundo de los encuentros con los estudiantes de Propaganda fide, Pío XI se refirió al "nacionalismo exagerado". El Papa diferenciaba entre tipos de "nacionalismo", uno "moderado" y otro "exagerado" que era criticado; marcaba la distinción entre la nación (y el nacionalismo moderado) y afirmaba que Dios ha hecho a las naciones. Hay lugar para un nacionalismo justo, moderado, templado, asociado a todas las virtudes, pero hay que protegerse del "nacionalismo exagerado" como de una verdadera maldición de divisiones y de guerras: Ci sono le nazioni e c'è anche il nazionalismo, e le nazioni le ha fatte Iddio $^{50}$. Dirigiéndose, ya en otoño de 1938, a los profesores de Acción católica, rechazó el racismo ("grosso e grave errore"), sin confundirlo con el nacionalismo exagerado que, sin embargo, es mencionado otra vez como aquel nacionalismo que no hermana a los pueblos sino que los arroja a los unos contra los otros ${ }^{51}$.

Ante ese nacionalismo conviene ejercer el discernimiento permanente con claridad entre la verdad y la apariencia engañosa, abrir el juicio a la voz de la razón guste o no guste y rechazar la huera retórica del error, tomando en serio las exigencias del derecho y la justicia no sólo cuando se trata de exigir los propios derechos, sino la justas exigencias de los demás pueblos, dijo Pío XII tan sólo dos años después (Grazie, 1940). El papa Pacelli siguió hablando de la nación en términos morales y espirituales, como sus predecesores León XIII y Pío XI, proponiendo su reflexión lejos de la inspiración positivista, anti-intelectualista, basada en los impulsos instintivos y las pasiones gregarias que oscurecen los caracteres racionales, jurídicos y morales de toda verdadera sociedad ${ }^{52}$, también advertía de aquel nacionalismo que niega todo al país ajeno y lo reivindica todo para el propio ${ }^{53}$ o que atribuye una pseudomajestad a la legislación positiva, a la producción jurídica totalitaria, pisoteando los derechos naturales de las personas físicas y morales ${ }^{54}$.

\footnotetext{
50 Pío XI (1938) Discorsi (ed. D. Bertetro), Roma 1961 (21985), Editrice Vaticana, 786: "Agli alunni del Collegio di Propaganda Fide" (28-VII-1938): Una cosa son las naciones y otra cosa el nacionalismo.

${ }^{51}$ Pío XI (1938) Discorsi (ed. D. BerTetro), Roma 1961 (21985), Editrice Vaticana, 796: "Ad insegnanti di Azione cattolica" (6-IX-1938).

52 Pío XII (1946) C'est un geste.

${ }^{53}$ Pío XII (1952) Nous vous souhaitons.

54 Pío XII (1950) L'importance.
} 
Pío XII partía de esa misma concepción cuando dos años más tarde decía en el radiomensaje Ecce ego de la Navidad de 1954, hablando también sobre la guerra fría, la construcción europea, el mercado, la guerra y el trabajo por la paz, se refería al nacionalismo con estas palabras:

La sustancia del error [nacionalista] consiste en confundir la vida nacional en sentido propio con la política nacionalista: la primera, derecho y gloria de un pueblo, puede y debe ser promovida; la segunda, germen de infinitos males, nunca será suficientemente rechazada. La vida nacional es, en sí misma, el complejo operante de todos aquellos valores de civilización que son propios y característicos de un determinado grupo, de cuya unidad espiritual constituyen como el vínculo. (...) En su esencia, la vida nacional no es algo político. Esto es tan cierto que, como demuestran la historia y la praxis, la vida nacional puede desarrollarse junto a otras [naciones] dentro del mismo Estado, como también puede extenderse más allá de los confines políticos de éste. La vida nacional fue un principio de disolución de la comunidad de los pueblos cuando comenzó a ser aprovechada como medio para fines políticos, esto es cuando el Estado dominador y centralizador hizo de la nacionalidad la base de su fuerza de expansión. Entonces nació el Estado nacionalista, germen de rivalidades e incentivo de discordias ${ }^{55}$.

Con Juan XXIII y el Concilio Vaticano II se impuso un tratamiento de las naciones desde la perspectiva de las relaciones internacionales. A partir de ese momento, el uso que haga el PSC de la palabra nación se identificará con "comunidad política independiente". Así pues, Juan XXIII en su encíclica social sobre la paz en la tierra hizo varias afirmaciones sobre las comunidades políticas que podemos $\operatorname{sintetizar}^{56}$ :

A. Tienen derecho a la existencia (medios necesarios y orientación de su propio desarrollo) deber de asegurar y proteger este derecho.

B. No han de procurar un aumento de riquezas que constituya injuria u opresión injusta de las demás naciones ${ }^{57}$.

C. No deben zanjar las diferencias económicas con las armas, el fraude o el engaño, sino por la razonable comprensión recíproca, el examen cuidadoso y objetivo de la realidad y un compromiso equitativo de los pareceres contrarios.

\footnotetext{
${ }_{55}^{5}$ Pío XII (1954) Ecce ego.

56 Juan XXIII (1963) Encíclica Pacem in terris, n. 91-93.

57 JuAN XXIII (1963) Encíclica Pacem in terris, n. 42-43, se refiere a aquella independencia económica que no siempre está conseguida con la independencia política, lo que cuatro años más tarde fue subrayado por PABLO VI (1967) Encíclica Populorum progressio, nn 6 y 65.
} 
Pablo VI también se refirió al nacionalismo como un obstáculo a superar para el desarrollo de los pueblos. Si tanto las naciones jóvenes como las de vieja cultura pueden estar celosas de su identidad u orgullosas de su patrimonio histórico, esos sentimientos legítimos deben ser sublimados por la caridad universal, que engloba a toda la familia humana ${ }^{58}$ : El nacionalismo aísla los pueblos en contra de lo que es su verdadero $b \operatorname{en}^{59}$ y es enemigo de la solidaridad universal y fuente de discriminaciones injustas ${ }^{60}$.

Coherentemente con estas posiciones, el Concilio Vaticano II reiteraba con estos términos la doctrina más consolidada: es necesario ampliar la mente humana

más allá de las fronteras de la propia nación, renunciar al egoísmo nacional y a la ambición de dominar a otras naciones ${ }^{61}$, acabar con (...) las ambiciones nacionalistas ${ }^{62}$ y cultivar como buenos ciudadanos verdadera y eficazmente el amor a la patria, evitando (...) el nacionalismo exagerado63.

\subsection{Verdadero alcance del "giro cultural-nacional" de Juan Pablo II}

Ya al comienzo de su pontificado Juan Pablo II trató del tema de la nación. Su discurso a la UNESCO en París (2-VI-1980) se tituló "La humanidad integral del hombre se expresa en la cultura". ${ }^{64}$ En ese discurso y en ese contexto, después de subrayar la misión y función de la UNESCO y de tratar de la significación esencial de la cultura como modo de existencia y como expresión de un humanismo inspirado religiosamente que implica conclusiones entre otros aspectos (educación,

\footnotetext{
${ }^{58}$ Pío XI había hablado de la fraternidad universal y de la familia humana (Ubi arcano, 1922: nn 22, 20), así como Pío XII lo hizo de solidaridad; en contraste declaraba que la política nacionalista [era] como el individualismo estatal de los últimos siglos (Negli ultimi 1946, Nous vous adressons 1950) y criticaba la mentalidad egocéntrica de los Estados (Gravi, 1949).

${ }^{59}$ PABLO VI (1967) Encíclica Populorum progressio, n 62.

${ }^{60}$ PABLO VI (1971) Carta Octogesima adveniens, n 17.

${ }^{61}$ Concilio Vaticano II (1965) Constitución pastoral Gaudium et spes, n 82.

$62 \mathrm{lbid}, \mathrm{n} 85$.

${ }^{63}$ Concilio Vaticano II (1965) Declaración Ad gentes, n 15.

${ }^{64}$ Cf. JUAN PABLO II (1980) Insegnamenti, Roma, Lib. Ed. Vaticana, III. 1 (1980, enero-junio) 1636-1655, consultable también en www.vatican.va.
} 
familia, comprensión antropológica) sobre realidad de la nación, el Papa hacía la intervención que supuso un giro significativo en el PSC, pues afirmó y subrayó la misión cultural de la nación.

El derecho a la nación está en la base del derecho a la cultura y a la educación. El derecho del hombre y de la mujer a "ser" más no sólo exigen el primado de la familia, sino "en la misma línea", el "derecho de la nación". ${ }^{65}$ A continuación Juan Pablo II dijo:

La nación es, en efecto, la gran comunidad de personas unidas por diversos vínculos, pero sobre todo, precisamente, por la cultura. La nación existe "por" y "para" la cultura, y así es ella la gran educadora de los hombres para que puedan "ser más" en la comunidad. La nación es esta comunidad que posee una historia que supera la historia del individuo y de la familia. En esta comunidad, en función de la cual educa toda familia, la familia comienza su obra de educación por lo más simple, la lengua, haciendo posible de este modo que el hombre aprenda a hablar y llegue a ser miembro de la comunidad, que es su familia y su nación ${ }^{66}$.

Cinco afirmaciones destacan en este texto que, por su importancia y significación, marca un verdadero giro en el PSC. El mismo Papa reconocía que sus ideas y convicciones nacían de su experiencia personal, como testigo y como hijo de una nación que ha sufrido diversas vicisitudes y experiencias históricas, de que aquélla conservó su identidad y su soberanía nacional apoyándose únicamente en su cultura ${ }^{67}$.

65 JUAN PABLO II (1980) Insegnamenti, cit., n. 14, 1647: "dans l'ensemble de l'œuvre de l'éducation de l'homme à une véritable humanité, il faut aussi situer dans la même ligne le droit de la Nation; il faut le placer lui aussi à la base de la culture et de l'éducation" (original en francés; en cursiva en el original). Como se puede comprobar ésta no es una definición tan distinta de la anteriormente citada de Jacques Maritain: Una nación es una comunidad de personas que toman conciencia de ellos mismas tal como la historia les ha hecho, se adhieren al tesoro de su pasado y se estiman tal como se reconocen o imaginan ser.

${ }^{66}$ JUAN PABLO II (1980) Insegnamenti, cit., nn. 14-15, 1647-1649.

${ }^{67}$ Declaraba papa Woityla:

mis palabras traducen una experiencia particular, un testimonio particular en su género. Soy hijo de una nación que ha vivido las mayores experiencias de la historia, que ha sido condenada a muerte por sus vecinos en varias ocasiones, pero que ha sobrevivido y que ha seguido siendo ella misma. Ha conservado su identidad y, a pesar de haber sido dividida y ocupada por extranjeros, ha conservado su soberanía nacional, no porque se apoyara en los recursos de la fuerza física, sino apoyándose exclusivamente en su cultura.

En el discurso ante la ONU (Nueva York 1995) reiteró la misma referencia: La historia demuestra que en circunstancias extremas (como aquellas que se han visto en la tierra donde he nacido)... 
1. La nación es un hecho sobre todo cultural: existe a partir y en función de la cultura.

2. El derecho de la nación no tiene relación con ningún "nacionalismo", sino con un conjunto estable de experiencias y de perspectivas de desarrollo humano.

3. La soberanía fundamental nacional se expresa culturalmente, pues parte de la soberanía antropológica como fundamento. ${ }^{68}$

4. Existen en Europa naciones con soberanía histórica basada en su cultura, que no tienen plenamente reconocida su soberanía [política].

5. La soberanía cultural debe orientar la actuación responsable de los medios de comunicación social y de la educación, junto a la misión esencial de la familia.

Además de esta inicial afirmación de 1980, ha habido a lo largo de todo el ejercicio ministerial petrino de Juan Pablo Il otras ocasiones en que se refirió a la cuestión nacional, entre ellas dos más destacadas, el Discurso al Cuerpo diplomático en 1988 y el Discurso ante la ONU en 1995. Intentaré presentar brevemente las sucesivas intervenciones de ese pontificado.

También en su primera encíclica social Laborem exercens sobre el trabajo humano (14-IX-1981), después de tratar sobre la dimensión personal del trabajo, lo hizo sobre las dimensiones familiar y social y en ésta se refirió a la nación como aquella

gran sociedad a la que pertenece el hombre sobre la base de particulares vínculos culturales e históricos. [... que] aunque no haya asumido todavía la forma madura de una nación es (...) una gran encarnación histórica y social del trabajo de todas las generaciones. Todo esto hace que el hombre concilie su más profunda identidad humana

\footnotetext{
${ }^{68}$ Mientras que Juan Pablo II dijo "Il existe une souveraineté fondamentale de la société qui se manifeste dans la culture de la Nation. II s'agit de la souveraineté par laquelle, en même temps, l'homme est suprêmement souverain", el texto es citado en el documento de los obispos de Cataluña, Al servei del nostre poble (27-12-1985) de esta manera: [L'Església (...) considera que] "hi ha una sobirania fonamental de la societat que es manifesta en la cultura de la nació. Es tracta de la sobirania per la qual I'home és, al mateix temps, sobirà suprem" (n. 14 del Discurso citado de Juan Pablo II, 2-Vl-1980). Si la última afirmación podría entenderse desde una soberanía absoluta originaria de la persona humana, nos parece que el original francés del discurso indica más bien que el origen de la soberanía cultural reside en la misma fuente que la soberanía original, sin ser absolutamente soberano en sí mismo. No es lo mismo ser "supremamente soberano" que "soberano supremo". La primera es la concepción clásica sostenida por muchos pensadores cristianos como Tomás de Aquino o Francisco Suárez, la segunda sería con diferencias la sostenida por los contractualistas barrocos de la soberanía a partir de los enunciados de Jean Bodin. En el citado discurso (n. 8) el Papa había dicho: "On ne peut penser une culture sans subjectivité humaine et sans causalité humaine; mais dans le domaine culturel, I'homme est toujours le fait premier: I'homme est le fait primordial et fondamental de la culture" (las cursivas son del original).
} 
con la pertenencia a la nación y entienda también su trabajo como incremento del buen común elaborado juntamente con sus compatriotas, dándose así cuenta de que por este camino el trabajo sirve para multiplicar el patrimonio de toda la familia humana, de todos los hombres que viven en el mundo (n. 10).

Finalmente, en un importante discurso ante Naciones Unidas en 1995, papa Wojtyla dedicó una parte a los derechos de las naciones y al respeto por las diferencias, no sólo entre las naciones. Es la última gran intervención papal sobre esta cuestión.

Cuatro son las grandes afirmaciones que deben subrayarse antes de comentar a continuación los silencios y los cambios de perspectiva entre el discurso de 1980 y el de 1995.

1. Derechos de las naciones. La Declaración Universal de Derechos Humanos (1948) en 1995 todavía no tiene un análogo acuerdo internacional que afronte los derechos de las naciones. En el origen de las guerras están la violación de esos derechos, la ignorancia por la única razón de ser consideradas [las naciones] "otras", en nombre de doctrinas nefastas que predican la "inferioridad" de algunas naciones y culturas. Existe un "derecho a la existencia" de la nación, que no puede ser negado por ninguna instancia, aunque no exige necesariamente una soberanía estatal, siendo posibles diversas formas de agregación jurídica entre diferentes naciones, que deben ser realizadas desde la libertad de la garantía del ejercicio de la autodeterminación. El derecho fundamental a la existencia implica para cada nación el derecho a la propia lengua y cultura, mediante las que un pueblo expresa y promueve lo que llamaría su originaria "soberanía" espiritual, que consigue que una nación sobreviva aun tras la pérdida de la propia independencia política y económica.

2. El patriotismo, amor a la nación propia, y el nacionalismo exacerbado. En este contexto hay que diferenciar entre una forma peligrosa de nacionalismo exacerbado (desprecio por las otras naciones o culturas) y el patriotismo (el justo amor por el propio país de origen, que nunca trata de promover el bien propio en perivicio de otras naciones). El nacionalismo, especialmente el más radical, se opone por tanto al verdadero patriotismo, y puede derivar en formas nuevas de totalitarismo.

3. Tensión entre particular y universal. El problema de las nacionalidades se sitúa hoy en un nuevo horizonte mundial, caracterizado por una fuerte "movilidad", que hace los mismos confines étnico-culturales de los diversos pueblos cada vez menos definidos, debido al impulso de múltiples dinamismos como las migraciones, los medios de comunicación social y la mundialización de la economía. 
En este horizonte, el surgimiento de los particularismos étnico-culturales es una especie de contrapeso a las tendencias homologadoras, lo que se debe valorar desde una reflexión profunda antropológica y ético-jurídica. Hay tres reflexiones urgentes a realizar en este horizonte: entender los "derechos de las naciones" como "derechos humanos" referidos específicamente a este aspecto de la vida comunitaria y reflexionar sobre estos derechos para evitar errores y orientarse hacia un orden mundial más justo; pero también es urgente una definición del concepto de "nación", así como en tercer lugar, tener en cuenta las exigencias de universalidad: la conciencia de los deberes de unas naciones con otras y con la humanidad entera, el deber de vivir con una actitud de paz, de respeto y de solidaridad y el fecundo "intercambio de dones" que refuerza la unidad entre todos los hombres y la conciencia de la diferencia.

4. Reconocimiento del "otro" y de su diferencia. En el mismo discurso subrayó la comprensión de la dimensión esencial de la diferencia del "otro". El miedo a la "diferencia", alimentado por resentimientos "históricos" y acrecentado por diversas manipulaciones, puede llevar a la negación de la humanidad misma del "otro", con "una espiral de violencia" de la que nadie queda libre. El miedo a la "diferencia", cuando se expresa mediante un reductivo y excluyente nacionalismo que niega cualquier derecho al "otro", puede conducir a una verdadera pesadilla de violencia y de terror. Ignorar o anular la realidad de la diversidad excluye la posibilidad de acceder a las profundidades del misterio de la vida humana: la verdad sobre el hombre es el criterio inmutable con el que todas las culturas son juzgadas, pero cada cultura tiene algo que enseñar acerca de una u otra dimensión de aquella compleja verdad. La "diferencia", para algunos amenazadora, mediante un diálogo respetuoso, puede ser fuente de una comprensión más profunda del misterio de la existencia humana ${ }^{69}$.

Nueve años más tarde, ya muy al final del pontificado de Juan Pablo II, llama, no obstante, la atención que el Compendio de la doctrina social de la lglesia de 2005 sólo le dedicase un párrafo, aunque importante (n. 157: "derechos de los pueblos y de las naciones").

Resumiendo las posiciones expresadas por Juan Pablo II, el Compendio afirma

El campo de los derechos del hombre se ha extendido a los derechos de los pueblos y de las Naciones, pues «lo que es verdad para el hombre lo es también para los pueblos». El Magisterio recuerda que el derecho internacional "se basa sobre el principio del igual respeto, por parte de los Estados, del derecho a la autodeterminación de cada

69 JUAN PABLO II (1995) Discurso a la quincuagésima asamblea general, ONU, Nueva York, 5-X-1995. 
pueblo y de su libre cooperación en vistas del bien común superior de la humanidad». La paz se funda no sólo en el respeto de los derechos del hombre, sino también en el de los derechos de los pueblos, particularmente el derecho a la independencia. // Los derechos de las Naciones no son sino "los "derechos humanos" considerados a este específico nivel de la vida comunitaria». La Nación tiene "un derecho fundamental a la existencia»; a la "propia lengua y cultura, mediante las cuales un pueblo expresa y promueve su "soberanía" espiritual"»; a "modelar su vida según las propias tradiciones, excluyendo, naturalmente, toda violación de los derechos humanos fundamentales y, en particular, la opresión de las minorías»; a "construir el propio futuro proporcionando a las generaciones más jóvenes una educación adecuada». El orden internacional exige un equilibrio entre particularidad y universalidad, a cuya realización están llamadas todas las Naciones, para las cuales el primer deber sigue siendo el de vivir en paz, respeto y solidaridad con las demás Naciones. ${ }^{70}$

Tres perspectivas, pues, resultan de este recorrido del pensamiento de Juan Pablo II: el derecho cultural para afirmar y preservar la subjetividad de un pueblo ("soberanía cultural", 1980; "soberanía espiritual", 1995), el derecho político para resolver la tensión entre patriotismo (amor a la propia nación) y nacionalismo exacerbado (absolutización de la propia nación) y el derecho internacional para garantizar las relaciones equilibradas entre universalidad y particularidad lo que implica interpretar el derecho a la independencia en el conjunto de tensiones binarias señaladas.

\section{Conclusión}

A lo largo del estudio creemos haber mostrado que el PSC no legitima ni ampara las pretensiones nacionalistas. Desde una prolongada atención a la realidad antropológica y cultural de la nación, el magisterio social pontificio contemporáneo se ha pronunciado de forma crítica y atenta sobre el fenómeno del nacionalismo. El estudio pretende mostrar la complejidad de la cuestión y la necesidad de una hermenéutica explícita para tratar de la nación y del nacionalismo. La nación como realidad natural no es identificable con el nacionalismo político. Por ello, la defensión de términos y de conceptos desde el punto de vista filosófico-político y

\footnotetext{
70 El citado Compendio alude sucesivamente a textos de JUAN PABLO II (1988) Sollicitudo rei socialis, $\mathrm{n}$. 33: AAS 80, 557-559; (1991) Centesimus annus, n. 21: AAS 83, 818-819; (1990) Carta con ocasión del $50^{\circ}$ aniversario del comienzo de la Segunda Guerra mundial, n. 8: AAS 82, 56; (1988), Discurso al Cuerpo Diplomático (9-I-1988), nn. 7-8: AAS 80, 1139; y (1995) Discurso a la Asamblea general de las Naciones Unidas (5-X-1995), n. 8. Los cinco documentos pertenecen a un período bastante corto -siete años, sobre veintisiete- de su pontificado; significativamente no es citado el discurso ante la UNESCO de 1980.
} 
jurídico es esenciales. La clarificadora reflexión que proviene de Jacques Maritain, sobre todo en su obra El hombre y el Estado (1949 en su primera versión inglesa, y 1953 en su definitiva edición francesa) permite una aproximación crítica al nacionalismo. Los conceptos equívocos necesitan una cuidadosa y crítica labor hermenéutica, si no se quiere derivar hacia posiciones excluyentes, arbitrarias o exageradas, en ningún caso fundamentadas. La posición crítica del PSC siempre ha considerado el llamado nacionalismo exagerado como una proposición no aceptable y ha valorado sin embargo el patriotismo, el verdadero amor a la patria. En la encíclica Pacem in terris (nn. 91-93) de Juan XXIII se afirma el derecho de las naciones a la existencia, sobre todo en aquel contexto de independencia de los llamados pueblos del "tercer mundo".

En 1980, tras el importante discurso en la UNESCO de París Juan Pablo II dejó abiertas interpretaciones más favorables a cierto nacionalismo, sobre todo de matriz cultural. Podríamos hablar de tres períodos diferenciados en el magisterio pontificio: el de los papas entre la primera guerra mundial y la segunda posguerra (1914-1958: Benito XV, Pío XI y Pío XII), la consideración de las naciones en el contexto de las relaciones internacionales y de la emergencia de los pueblos hasta entonces sometidos al nacionalismo (Juan XXIII) y la incorporación de la subjetividad antropológica colectiva como factor de afirmación nacional (Juan Pablo II) que es el que hemos llamado "giro cultural-nacional que el Papa vinculó también a su experiencia personal y social de una nación -Polonia- que había subsistido más de dos siglos sin ser Estado y, sin embargo, había conservado su subjetividad como pueblo. Este discurso supuso cambios no sólo semánticos sobre la nación, sino que abrió nuevas perspectivas, profundizando en la dimensión antropológico-cultural de la nación. Los sucesivamente matizados pronunciamientos de Juan Pablo II pueden legitimar posiciones nacionalistas políticas; tampoco se han producido cambios significativos en el magisterio posterior.

Podemos proponer como conclusiones del trabajo las siguientes afirmaciones e hipótesis para seguir avanzando: a lo largo de más de un siglo la evolución del PSC ha sido muy moderada; el patriotismo universalista es la proposición coherente del magisterio social que reconoce la tensión entre identidad cultural con una tradición (nacionalismo cultural) y vocación de pertenencia a una comunidad universal; el alcance del "giro nacional-cultural" de los años finales del siglo XX fue limitado y no modificó en lo esencial la posición anterior constante, aunque abrió nuevas perspectivas. Por último, es necesario subrayar el interés de una metodología hermenéutica que sustituya a una doctrina afirmada de forma abstracta para la que se aducen oportuna -o inoportunamente- argumentos de autoridad para justificar previamente posiciones adoptadas; por el contrario, una hermenéutica 
crítica tendrá en cuenta el deslizamiento conceptual y los efectos negativos no pretendidos en cada una de las posiciones antes de argumentar sobre las mismas, y por ello hará un cuidadoso estudio del sentido de las palabras usadas y de los posibles límites de su utilización.

Como conclusión general, podemos afirmar que el PSC acepta el valor de la nación como realidad histórica-cultural, no siempre identificable con un Estado soberano. El magisterio pontificio subraya el valor del patriotismo, del amor a la tierra patria, a la vez que subraya los límites de éste cuando se convierte en un nacionalismo inmoderado que desvirtúa ese valor y absolutiza la nación como sujeto político autónomo, independiente de su configuración. Por último, el magisterio pontificio, aun reconociendo, el papel central de la nación como sujeto histórico, nunca ha pretendido legitimar las posiciones de los nacionalismos que reclaman para la nación una configuración política como Estado independiente y soberano.

\section{Bibliografía}

Aux, CH. (1962) Le Saint-Siège et le nationalisme en Europe (1870-1960), París 1962, Sirey.

Bonet y Baltà, J., MANent, A. y Martí, C. (1981) "Contribució de l'Esglèsia catalana a la conformació de la nacionalitat catalana als segles XIX i XX": Qüestions de vida cristiana, n' 109 (sobre L'Església i la nacionalitat catalana), 29-42.

CALSINA, M. (2013) [Entrevista a Joan Rigol] "La responsabilitat democràtica que et dóna el país fa que el teu interlocutor no tingui dret de veto": Qüestions de vida cristiana, $\mathrm{n}^{\circ} 247$ (sobre La independència), 53-68.

CARDÚS, S. (2013) "L'Esglèsia catalana i el procés independentista. Una fotografia fixa i, per tant, moguda": Qüestions de vida cristiana, ${ }^{\circ} 247$ (sobre La independència) 33-40.

CarRasco y Calvo, S. (1981) "Neotomisme, nacionalisme i catolicisme social": Qüestions de vida cristiana, $\mathrm{n}^{\circ} 109$ (sobre L'Església i la nacionalitat catalana), 64-88.

Carrera y Carrera, J. (2015) "¿̇lndependencia o independencias?": Razón y Fe 273 [n. 1407], 39-48. 
CASTINEERA, À. (2013) "Com transitar per terreny deconegut": Qüestions de vida cristiana, n 247 (sobre La independència), 9-17.

Centro Pignatell (1994) Los nacionalismos, Zaragoza, Gobierno de Aragón - Departamento de Educación y Cultura.

ChaBOD, F. (2002) L'idea di nazione, Bari, Laterza.

Compte Grau, M.T. (2005) "El nacionalismo en la Doctrina Social de la Iglesia", en Rico Pavés, J. y Pérez-Soba Diez del Corral, J. J. (dirs.) Terrorismo y nacionalismo. Comentario a la Instrucción Pastoral de la Conferencia Episcopal Española. Valoración moral del terrorismo en España, de sus causas y de sus consecuencias, Madrid, Católica - Biblioteca Autores Cristianos (BAC), 361-442. Disponible también para consulta electrónica en Instituto Social León XIII; http://www.instituto-social-leonxiii.org/index.php/estudios/

- (2002) "La nación y los derechos de las comunidades nacionales", en Souto CoelHo, J., Doctrina social de la Iglesia. Manual abreviado, Madrid, Biblioteca Autores Cristianos (BAC) - Fundación Pablo VI, 459-478.

CONSEJO DE REDACCIÓN (2016) "España y Cataluña: la reconstrucción de un pacto": Revista de Fomento Social 71 (2016), 5-53.

Costa y BOU, J. (2000) Nació i nacionalismes. Una reflexió en el marc del Magisteri pontifici contemporani, Barcelona, Facultat de Teología de Catalunya (en castellano: Madrid 2000, AEDOS-Unión).

- (2013) "Nació i nacionalismes: principals aportacions del Papa Joan Pau II": Qüestions de vida cristiana, $\mathrm{n}^{\circ} 247$ (sobre La independència), 41-51.

Cotellessa, S. (2004) "Nazione": Dizionario di Dottrina Sociale della Chiesa. Scienze sociale e Magistero, Milán, Vita e Pensiero (Universittà Cattolica del Sacro Cuore-CRSDSCH), 945.

DuCH, Ll. (1981) "Perspectiva político-teològica de la nació catalana": Qüestions de vida cristiana, n 109 (sobre L'Església i la nacionalitat catalana), 16-28.

- (2011) "Consideraciones antropológicas sobre identidad y tradición, a partir del documento episcopal Raíces cristianas de Cataluña (1985)": Revista de Fomento Social 66, 73-85. 
EGGER, J. (1998) Iglesia y minorías étnicas, Bilbao, Desclée de Brouwer.

FornÉ, J. M. (2013) "La independencia (de Catalunya) i l'universal": Qüestions de vida cristiana, $\mathrm{n}^{\circ} 247$ (sobre La independència), 19-31.

González CASANOVA, J. A. (1981) "Pàtria, nació, poble": Qüestions de vida cristiana, n 109 (sobre L’Església i la nacionalitat catalana), 8-15.

Gutiérrez García, J. L. (1971) Conceptos fundamentales en la Doctrina Social de la Iglesia, Madrid, Centro de Estudios Sociales del Valle de los Caídos, III, 161-175, $351-356$ y $545-550$.

GutiérRez García J. L. (1973) La concepción cristiana del orden social, Madrid, Centro de Estudios Sociales del Valle de los Caídos, (236-242).

HAYES, C. (1960) Nationalism: a religion, Nueva York, McMillan.

Hermet, G. (1996) Histoire des nations et du nationalisme en Europe, París, Seuil.

JobIN, J. (1994) Los pueblos autóctonos. La enseñanza de Juan Pablo II, Bogotá, Celam.

LLOBERA, J. R. (1996) El Dios de la modernidad: el desarrollo del nacionalismo en la Europa occidental, Barcelona, Anagrama.

MARITAIN, J. (1988) L'Homme et l'État (Chicago 1949, París 1953), en J. y R. MARITAIN (1990) OEuvres complètes (1947-1951) 9, 471-736.

MASNOU BOIXEDA, R. (1996) Carta sobre nacionalismos, Barcelona, Península.

- (1999) El problema catalán. "Reflexiones para el diálogo", Madrid, Encuentro.

MASSOT y MUNTANer, J. (1981) "El Vaticà i Catalunya": Qüestions de vida cristiana, n 109 (sobre L'Església i la nacionalitat catalana), 43-62.

de Obieta Chalbaud, J. A. (1985) El derecho de autodeterminación de los pueblos, Madrid, Tecnos.

Oriol Tataret, A. M. y Costa, J. (2003) Fet nacional i magisteri social de l'Església, Barcelona, Proa (en castellano: Barcelona, Tibidabo). 
Prat y Pons, R. (2013) "Autonomia. Independència. Interdependència": Qüestions de vida cristiana, $\mathrm{n}^{\circ} 247$ (sobre La independència), 133-153.

RAGUER, H. (22016) Ser independentista no és cap pecat. L'Esglèsia i el nacionalisme català, Claret, Barcelona.

RECALDE, J. R. (1982) La construcción de las naciones, Madrid, Siglo XXI.

Sáez de la Fuente Aldama, I. (2002) El movimiento de liberación nacional vasco, una religión de sustitución, Bilbao, IDTP y Desclée de Brouwer.

SOler, J. M. (2013) "Els valors del catalanisme, com a factor de cohesió social": Qüestions de vida cristiana, $n^{\circ} 247$ (sobre La independència), 155-163.

Soley Climent, J. (2014) "Las distorsiones nacionalistas de la doctrina social de la Iglesia y la secularización de Cataluña": Cristiandad, 1-I-2014.

StURZO, L. (1960) Nacionalismo e internacionalismo (Opera omnia, I-10, Roma 1946, Istituto Luigi Sturzo; reedición, Soveria Manelli (Italia) 2007, il Rubbetino); trad. castellana, Buenos Aires, Del Atlántico.

\section{Anexo: tomas de posición de la Doctrina social de la Iglesia tras el giro en la cuestión nacional (1870)}

a. Encíclicas de León XIII (papa 1878-1903).

1. Inscrutabili Dei consilio (programa pontificio), 21-IV-1878, n. 19.

2. Quod apostolici muneris (sobre el socialismo), 28-XII-1878 (28-XI), n. 5-6.

3. Grande munus (sobre países eslavos), 30-IX-1880 (12-II-1880).

4. Diuturnum illud (sobre la autoridad civil), 29-VI-1881, nn. 3-4, 8 y 19 : AL 2, 272.

5. Licet multa (sobre Iglesia en Bélgica), 3-VIII-1881.

6. Etsi Nos (sobre política en Italia), 15-II-1882.

7. Cum multa sint (sobre Iglesia en España), 8-XII-1882, nn. 1, 4 y 7.

8. Nobilissima gallorum gens (sobre la Iglesia en Francia), 8-II-1884, n. 1. 
9. Humanum genus (sobre el relativismo y la masonería), 20-III-1884, n. 15.

10. Immortale Dei (sobre los católicos en el Estado), 1-I-1885, nn. 2, 8, 10 y 13-15.

11. lampridem (sobre la Iglesia en Alemania), 6-1-1886.

12. Pergrata nobis (sobre la Iglesia en Portugal), 14-IX-1886.

13. Officio Sanctissimo (sobre la Iglesia en Baviera), 22-XII-1887.

14. Libertas praestantissimum (sobre libertad y liberalismo), 20-VI-1888, nn. 17 y $31-32$.

15. Saepe Nos (sobre Irlanda), 24-VI-1888.

16. Etsi cunctas (sobre la Iglesia en Irlanda), 21-XII-1888.

17. Sapientiae christianae (sobre los cristianos como ciudadanos), 19-1-1890, n. 3-4, 6-13.

18. Dall'alto dell'Apostolico Seggio (sobre masonería en Italia), 15-X-1890.

19. Au milieu des sollicitudes (sobre Iglesia y Estado en Francia), 16-II-1892, nn. 15-16.

20. Notre consolation, 3-V-1892.

21. Inimica vis (sobre masonería), 8-XII-1892.

22. Custodi di quella fede (sobre la masonería), 8-XII-1892.

23. Constanti Hungarorum (sobre la Iglesia en Hungría), 2-IX-1893.

24. Caritatis providentiaeque nostrae (sobre la Iglesia en Polonia), 19-III-1894.

25. Inter graves, sobre la situación de la Iglesia católica en Perú (1-V-1894.

26. Praeclara gratulationis, 20-VI-1894.

27. Longinqua (sobre la Iglesia Estados Unidos de América), 6-I-1895.

28. Caritatis studium (sobre la Iglesia en Escocia), 25-VII-1898.

29. Spesse volte (sobre algunas instituciones católicas), 5-VIII-1898.

30. Graves de communi re (sobre la democracia cristiana, 18-I-1901.

31. Gravissimas (sobre las órdenes religiosas en Portugal), 16-V-1901.

32. Reputantibus (sobre Bohemia), 20-VIII-1901.

33. Annum ingressi, 19-III-1902. 
34. In amplissimo (sobre la Iglesia en Estados Unidos de América), 15-IV-1902.

35. Quae ad Nos (sobre la Iglesia en Bohemia y en Moravia), 22-XI-1902.

b. Pío X (papa 1903-1914)

1. Vehementer nos (sobre la situación en Francia), 11-II-1906.

2. Notre charge apostolique (sobre relaciones Iglesia-Estado), 23-IX-1910.

c. Benito XV (papa 1914-1922)

1. Exhortación Allorchè fummo, 28-VII-1915.

2. Nota Dès le debut, proponiendo la paz, 1-VII-1915.

3. Diuturni (carta al episcopado alemán), 15-VII-1919.

4. Amor ille singularis (carta al episcopado francés), 7-X-1919.

5. Carta al cardenal Gasparri, 3-XI-1919.

6. Pacem Dei munus, 23-V-1920.

d. Pío XI (papa 1922-1939)

1. Encíclica Ubi arcano, 23-XII-1922: AAS 14 (1922) 673-700 (682).

2. Encíclica Quas primas, 11-XII-1925: AAS 14 (1922) 673-700.

3. Carta al cardenal Andrieu Nous avons lu, 5-IX-1926.

4. Encíclica Divini illius magistri, 31-XII-1929: AAS 22 (1930).

5. Discurso a los cardenales y a la curia (24-XII-1930): Bertetto II, 456-464.

6. Encíclica Quadragesimo anno, 15-V-1931: AAS 23 (1931) 177-228 $(207,212)$.

7. Encíclica Non abbiamo bisogno, 29-VI-1931.

8. Encíclica Caritate Christi compulsi, 3-V-1932: AAS 24 (1932) 177-194 (179-180).

9. Encíclica Mit brennender Sorge, 14-III-1937, nn. 8, 12-14, 34-38: AAS 29 (1937) 145-167 (149, 152). ${ }^{71}$

\footnotetext{
${ }^{71}$ Texto oficial en alemán; en pp. 168-188 texto italiano.
} 
10. Alle suore di Nostra Signora del Cenacolo, 15-7-1938, Bertetto III, 766-772.

11. Agli Assistenti ecclesiastici dei Giovanni dell'Azione Cattolica, 21-7-1938, ib. 772-775.

12. Agli alunni del Collegio di Propaganda Fide, 28-7-1938, ib. 777-784.

13. Agli alunni di Propaganda Fide, 21-8-1938, ib. 784-787.

14. Ad insegnanti di Azione cattolica, 6-9-1938, ib. 793-798.

e. Pío XII (1939-1958)

1. Encíclica Summi pontificatus 20-X-1939: AAS 31 (1939) 413-453 $(428-429,440) .^{72}$

2. Radiomensaje In questo giorno 24-XII-1939: AAS 32 (1940) 5-13.

3. Alocución Grazie vi diciamo, 24-XII-1940: AAS 33 (1941) 5-14 (11-12).

4. Radiomensaje La solennità della Pentecoste: AAS 33 (1941) 195-205 (202).

5. Alocución In questo giorno solemne, 27-X-1941: AAS 33 (1941) 10-11.

6. Radiomensaje Con sempre 1942: AAS 35 (1943) 9-24 (11, 14, 21).

7. Alocución La vostra gradita presenza 13-VI-1943: AAS35(1943) 171-179 (174).

8. Alocución E ormai passato 1944: AAS 36 (1944) 166-175 (174).

9. Radiomensaje Oggi, al compierse 1-IX-1944: AAS 36 (1944) 249-258 (250).

10. Benignitas et humanitas 7-10, 15-16, 18, 24, 41-42 (AAS 37 (1945) $11-16,21)$.

11. Nell'accogliere 34-36: AAS 37 (1945) 166.

12. Dacche piacque 16 (AAS 37 (1945) 259).

13. Negli ultimi 13, 18-19: AAS 38 (1946) 19-21.

14. C'est un geste nn 3, 4, 5, 7: AAS 38 (1946) 262, 316-317.

15. La festività 12-13 (AAS 40 (1948) 10).

${ }^{72}$ A continuación se publican las traducciones en italiano, francés, castellano, inglés y alemán. 
16. Nous sommes 4: AAS 40 (1948) 508.

17. Gravi 18, 20, 25: AAS 41 (1949) 10-12.

18. Radiomensaje al pueblo 21-IX-1949. ${ }^{73}$

19. L'importance 20: AAS 42 (1950) 225-226.

20. Nous vous adressons 6: AAS 42 (1950) 486.

21. Nous vous souhaitons 8-10, 12-13: AAS 44 (1952) 820-821.

22. Ci riesce 5: AAS 45 (1953) 795.

23. Radiomensaje Ecce ego 24-XII-1954, 12, 25-27, 29, 33: AAS 47 (1955) $18,22-25$.

24. Il programma 6-8, 16-17: AAS 47 (1955) 765-766, 770-771.

25. Col cuore aperto 17: AAS 48 (1956) 40.

26. Alocución a la Colonia de Le Marche, Roma, 23-3-1958.

f. Juan XXIII (1958-1963)

1. Encíclica Pacem in terris, 3-VI-1963: AAS 55 (1963). ${ }^{74}$

\footnotetext{
${ }^{73}$ No está en Discorsi e radiomessaggi.

${ }^{74} \mathrm{~N}$ 37: los ciudadanos de un Estado autónomo o independiente.

$\mathrm{Nn}$ 42-43: la independencia política no siempre coincide con la independencia económica.

N 55: el bien común íntegro.

N 61: la estructura de los poderes públicos no es definitiva.

$\mathrm{N}$ 80: la ley natural debe regular las relaciones entre Estados.

$\mathrm{N}$ 86: relaciones internacionales.

N 89: vitalidad y desarrollo de las minorías, diferencias entre comunidades políticas.

N 90: mutuo conocimiento de los pueblos.

$\mathrm{N}$ 92: derecho de las comunidades políticas al desarrollo.

N 94: minorías étnicas: independencia o sometimiento .

N 119: controversias y negociaciones.

$\mathrm{N}$ 120: relaciones internacionales en libertad.

$N$ 123: ayuda en libertad.

Nn 130-131: ningún país aislado puede garantizar su progreso.

N 135: insuficiencia de los Estados para promover el bien común.

N 136: reconocimiento de derechos para todos los pueblos y naciones.

$N$ 138: igualdad y dignidad jurídica de las naciones.
} 
g. Concilio Vaticano II (1962-1965)

1. Constitución pastoral Gaudium et spes (7-XII-1965), nn. 30, 42-43, 74, 75, 82, 85: AAS 58 (1966) 1060-1063, 1106-1108.

2. Decreto Ad gentes (7-XII-1965), n. 15: AS 58 (1966) 962.

h. Pablo VI (1963-1978)

1. Encíclica Populorum progressio sobre el desarrollo de los pueblos, 24III-1967, nn. 6, 10, 62, 65, 77: AAS 59 (1967) 260, 262, 287-289, 295.

2. Carta apostólica Octogesima adveniens 14-V-1971, n. 17: AAS 63 (1971) 413.

i. Juan Pablo II (1978-2005).

1. Encíclica Redemptor Hominis (1979) n 17: AAS 71.

2. Discurso ante la UNESCO, París (2-VI-1980) AAS 72.

3. Discurso al Cuepro diplomático (14-1-1984).

4. Encíclica Laborem exercens sobre el trabajo humano (14-IX-1981) n 10: AAS 73.

5. Discurso al Cuerpo diplomático (9-I-1988), nn. 7-8: AAS 80, 1139.

6. Encíclica Sollicitudo rei socialis sobre el desarrollo de los pueblos (27XII-1987), n 33, 39: AAS 80 (1988) 557-559.

7. Mensaje en $50^{\circ}$ aniversario del comienzo de la segunda guerra mundial, (26-VIII-1989), nn. 2 y 8: AAS 82 (1990) 51 y 56.

8. Encíclica Centesimus annus (1-V-1991), n. 21, 27, 58: AAS 83 (1991) 818-819.

9. Mensaje en $50^{\circ}$ aniversario del final de la segunda guerra mundial (8-V-1995).

10. Discurso ante la ONU en 1995 Discurso a la Asamblea general de las Naciones Unidas (5-X-1995), n. 8: AAS 87 (1995).

i. Benito XVI (2005-2013)

1. Compendio de la doctrina social de la Iglesia 2005 (n. 157: "derechos de los pueblos y de las naciones"). 
k. Francisco (2013-)

1. Discurso en el Encuentro con los estudiantes y el mundo académico. Bolonia, Italia, (1-X-2017).

2. Discurso a la Conferencia Repensando Europa (Re-Thinking Europe), organizada por la COMECE en colaboración con la Secretaría de Estado. Roma (28-X-2017).

3. Discurso en el encuentro con autoridades, sociedad civil y cuerpo diplomático. Vilnius, Lituania (22-IX-2018). 